OPEN ACCESS

Edited by: Niwat Srisawasdi, Khon Kaen University, Thailand

Reviewed by:

Patcharin Panjaburee, Mahidol University, Thailand Antonio Granero-Gallegos, University of Almería, Spain

*Correspondence: Huy P. Phan hphan2@une.edu.au

Specialty section: This article was submitted to Educational Psychology, a section of the journal Frontiers in Psychology

Received: 14 July 2021 Accepted: 07 September 2021 Published: 30 September 2021

Citation:

Phan HP and Ngu BH (2021) Interrelationships Between

Psychosocial, Motivational, and Psychological Processes for Effective Learning: A Structural

Equation Modeling Study.

Front. Psychol. 12:740965. doi: 10.3389/fpsyg.2021.740965

\section{Interrelationships Between Psychosocial, Motivational, and Psychological Processes for Effective Learning: A Structural Equation Modeling Study}

\author{
Huy P. Phan* and Bing H. Ngu \\ School of Education, University of New England, Armidale, NSW, Australia
}

We tested a theoretical-conceptual model that introduced our recently developed psychological concept, termed as psychological processes, which is defined as "a person's continuing frame of mind to focus on disposition toward strong resolute, structured thoughts and organization, and aspiration to strive for educational success." This proposition is innovative as it considers the notion that a person's mindset is malleable and, importantly, subjects to social experiences derived from a situated social context. Moreover, from our definition, we contend that psychological processes, as a distinct construct, is "latent," or underlying, with three comparable psychological attributes: personal resolve, effective functioning, and personal striving. Our conceptualization, acknowledging the importance of social contexts and individualized experience and personal belief, proposed that perceived social experiences (i.e., positive versus negative), as a source of information, would shape a student's psychological processes, his/her state of motivation, and engagement in different types of adaptive outcomes. Moreover, from our point of view, psychological processes would act as a predictor as well as a potential mediator of motivation and engagement in different types of adaptive outcomes. In a similar vein, from the positive effect of psychological processes, motivation could act as a predictor as well as a mediator of adaptive outcomes. Structural equation modeling, from Taiwanese university students' ( $N=739$ ) responses to various Likert-scale measures, showed support for our original a priori model - for example, the positive effects of perceived social experiences on psychological processes $(\beta=0.81, p<0.001$ ) motivation $(\beta=0.61, p<0.001)$, and adaptive outcomes $(\beta=0.36, p<0.01)$, and the positive effect of psychological processes on motivation $(\beta=0.31, p<0.01)$. Interestingly, we also found some interesting findings with regard to the effects of measured indicators - for example, the positive effect of personal resolve, as a measured indicator, on adaptive outcomes 
( $\beta=0.28, p<0.001)$, and the effect of self-efficacy, as a measured indicator, on academic liking experience, also a measured indicator $(\beta=0.12, p<0.01)$. Overall, the results established have a wide range of implications for consideration - for example, the development of an educational program and/or instructional design that could promote and foster positive learning experiences.

Keywords: psychological processes, motivation, adaptive outcomes, schooling experience, optimal best, perceived social experiences, positive psychology, optimization

\section{INTRODUCTION}

One notable research inquiry in the field of Educational Psychology has emphasized the importance of effective learning and enriched schooling experiences. This focus, interestingly, has involved researchers and educators using different theoretical orientations as grounding for their conceptualizations. Recently for example, drawing from the paradigm of positive psychology (Seligman, 1999, 2010; Seligman and Csíkszentmihályi, 2000), we developed the theory of human optimization (Phan et al., 2017b, 2019b, 2020b), which seeks to provide theoretical understanding into the dynamics of "optimal best" (Fraillon, 2004; Phan et al., 2016c). Optimal best, reflecting positive schooling experiences, emphasizes a person's fullest capability in a subject matter (i.e., the maximization of a student's cognitive functioning in a subject matter in school). How a student achieves optimal best and/or effective learning in school contexts is a pervasive question that is noteworthy for consideration.

Achieving optimal schooling experiences, we contend, requires some form of "optimization" or motivation (Phan and Ngu, 2019a). For example, in a recent study that involved secondary school students (Phan and Ngu, 2021a), we found that a psychological concept known as "personal resolve" (Phan et al., 2017b, 2018,b) actually accounted for an improvement in optimal best. In a study that consisted of university students (Phan et al., 2019d), likewise, we found that aside from personal resolve, three other constructs also predicted optimal best: motivation toward learning, current level of best practice, and proactive social relationship. Thus, from this brief introduction of our current research undertakings and in tandem with existing research inquiries in the area of student motivation (e.g., Diseth, 2011; Martin et al., 2013; Collie et al., 2015), we contend that there are comparable and comparative psychological models, which may have practical relevance and explain the dynamics of optimal best and effective learning. Our collective research interest has led to our continuing development of different conceptualizations for investigation (e.g., Phan et al., 2019d, 2020e; Phan and Ngu, 2021a), which in turn could advance the study of optimal best (Fraillon, 2004; Phan et al., 2016c, 2017b). One such conceptualization, as reported in the present empirical article, capitalizes on the use of the statistical technique of structural equation modeling (SEM) (Schumacker and Lomax, 2004; Kline, 2011).

The significance of our research inquiry, as discussed in this empirical article, entails an examination of a theoretical model (see Figure 1), which considers the interrelationships between three major theoretical orientations of effective learning: psychosocial experiences, psychological processes, and motivational beliefs. Specifically, our focus of inquiry, which consists of university students in Taiwan ( $N=442$ women, 297 men), entails two different structural pathways of analysis: the hypothesized a priori effects of four distinct latent theoretical concepts, denoted as $\mathrm{L}_{1}$ predictive effects, and the potential a posteriori effects of the corresponding measured indicators, denoted as $\mathrm{L}_{2}$ predictive effects. This consideration of both $\mathrm{L}_{1}$ and $\mathrm{L}_{2}$ predictive effects is insightful, theoretically and methodologically, allowing us to have clearer understanding into the operational nature of psychosocial, psychological, and motivational factors of students' learning. More importantly, aside from theoretical and methodological contributions, our obtained correlational findings are of relevance for educators and students alike for example, the effective utilization of psychological processes, which may facilitate the achievement of optimal best.

\section{AN INTEGRATED FRAMEWORK FOR DEVELOPMENT: INTRODUCTION}

Fostering enriched learning experiences in academic contexts is an important endeavor for development. In the field of research of Educational Psychology, for example, educators and researchers have inquired into different theoretical orientations that could promote and account for effective learning. Capitalizing on this development, we conceptualize a theoretical model, which incorporates three major orientations for examination: psychosocial influences, psychological processes, and motivational beliefs. This proposition for examination, as shown in Figure 1, is situated within the framework of structural equation modeling (SEM) (Schumacker and Lomax, 2004; Kline, 2011), which consists of a latent factor (i.e., a latent factor is known as $\xi_{n}$, where $\left.n=1,2,3, \ldots\right)$ and its defined measured indicators (i.e., a measured indicator is known as $\mathrm{X}_{n}$, where $n=1$, $2,3, \ldots .$.$) . Our conceptualization connotes three distinct latent$ factors, corresponding to the three major theoretical orientations: psychosocial influences $\left(\xi_{1}\right)$, psychological processes $\left(\xi_{2}\right)$, and motivational beliefs $\left(\xi_{3}\right)$. Each latent factor is defined by three measured indicators (e.g., $\xi_{1} \rightarrow \mathrm{X}_{1}, \mathrm{X}_{2}$, and $\mathrm{X}_{3}$ ) where, in turn, each measured indicator is a composite score of item responses. This methodological approach is significant as it enables us to examine and identify associative patterns of both latent factors (i.e., $\mathrm{L}_{1}$ predictive effects) and measured indicators (i.e., $\mathrm{L}_{2}$ predictive effects). For clarity, Table 1 summarizes the definition 


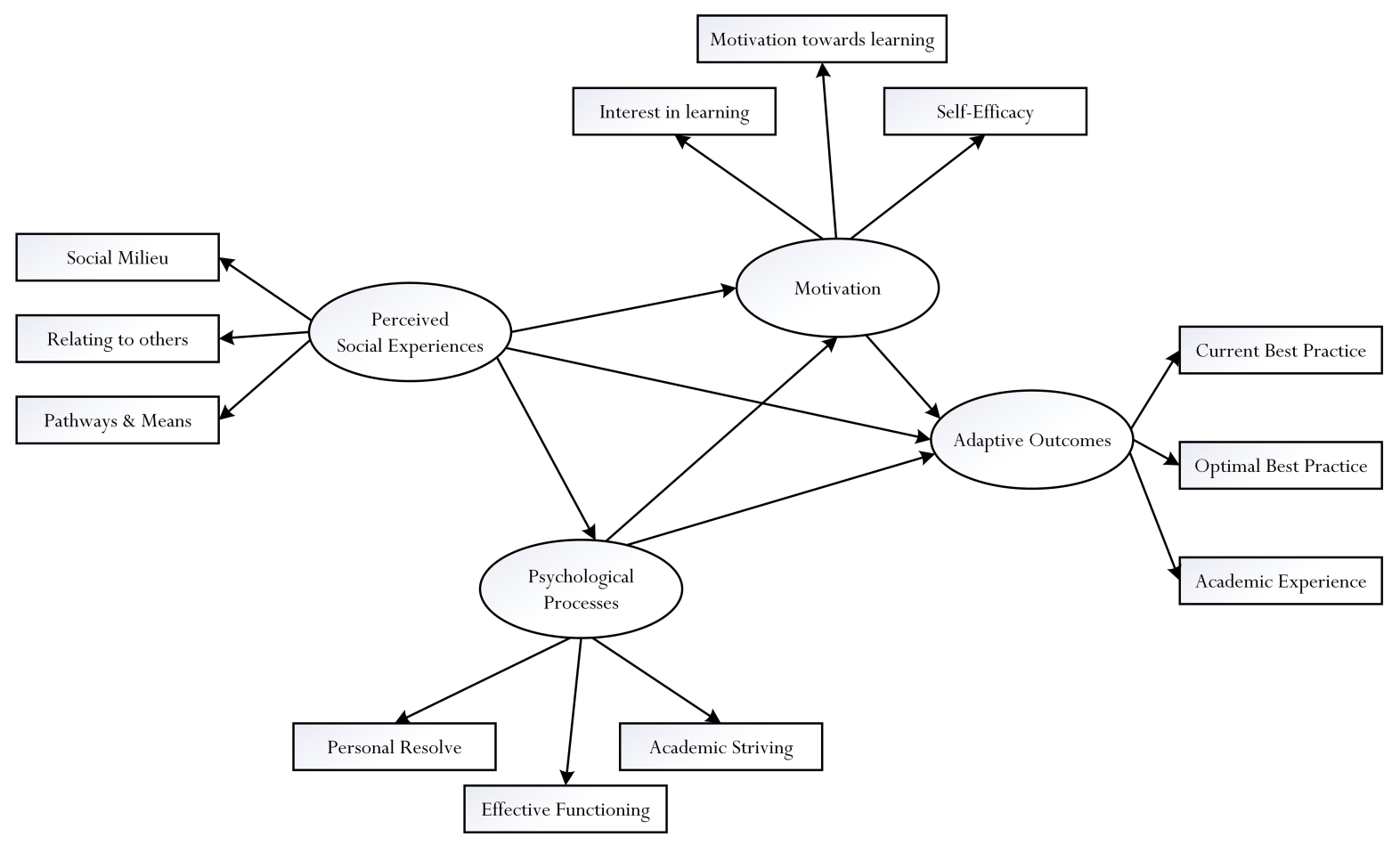

FIGURE 1 | Conceptual model for examination.

and the description of the nature of each measured indicator. In the next section of the article, we provide an overview of the potential relationships between the three latent factors and their respective measured indicators.

\section{The Importance of Perceived Social Experiences}

There is extensive research, which has focused on the importance of the social context. Vygotsky (1978) sociocultural theory of cognition, for example, places emphasis on the social processes that a person, for example, would internalize his learning and understanding about Psychology 101 from peers and capable others. Bronfenbrenner (1989) bioecological systems theory, similar to Vygotsky (1978) theory, discusses the importance of situated sociocultural influences. Roorda et al. (2011) metaanalysis of engagement, likewise, details the impact of the social environment. According to the authors, a social environment is perceived as being positive when opportunities arise for proactive social relationships (e.g., teacher-student social relationship: Hawkins et al., 2010; Allen et al., 2013; Gallagher, 2013). Why is this the case? A student is more inclined to have a favorable view when a teacher or an educator is able to provide social support and emotional security. This premise, in part, reflects the nature of attachment theory (Ainsworth et al., 1978; Ainsworth, 1979; Stevenson-Hinde and Verschueren, 2002), which emphasizes a student's need to seek emotional and social bonding.

From the perspective of schooling and academia, it is poignant for students to perceive positive social experiences. Perceived enriched social experiences, such as a positive teacher-student relationship (TSR) (Roorda et al., 2011) would assist to facilitate school, or academic, adjustment, resulting in improved academic and non-academic performances. In the context of the present study, we define a student's perceived social experiences, $\xi_{1}$, as being a composite, or an amalgamation, of the following: the student's perception of the social milieu itself $\left(\mathrm{X}_{1}\right)$, the student's ability to socially relate to others at school $\left(\mathrm{X}_{2}\right)$, and the student's perception that there are pathways and means for academic growth $\left(\mathrm{X}_{3}\right)$. Positive social experience at school (e.g., supporting friendship with a peer) is effective (Roorda et al., 2011; Whannell and Allen, 2011) as it helps students to adjust and to improve their academic performance outcomes. For example, in line with Vygotsky $(1978,1981)$ sociocultural theory of cognition, a student may actively interact and seek academic support from a teacher and/or from a peer who is more capable in the subject matter.

Aside from proactive social relationships at school, opportunities, pathways, and/or means for personal growth in academic learning and/or personal well-being (Li et al., 2008; Soutter, 2011; Waters et al., 2017) are also encouraged. For example, in a recent study, which involved university students, Phan et al. (2019c) found that relating to others accounted for an improvement in positive emotional well-being. In a similar study that consisted of secondary school students in Taiwan, Phan and Ngu (2020a) noted that proactive social relationship between teachers and students predicted personal and positive emotional well-being. Peer-peer social relationship, in contrast, predicted personal well-being and personal striving. From our point of view, taking into consideration this line 
TABLE 1 | A summary of definitions.

\section{Measured Indicator Definition}

\section{Perceived social experiences \\ Perceived social experiences}

Social Milieu

The social milieu, according to Phan et al. (2019c), is defined as "the totality of the 'sociocultural climate' of a neighborhood where a family resides, a local community that a person is in, and a school that a student attends. The social milieu of a community (e.g., school), in this case, emphasizes the inclusiveness of sociocultural settings and influences, which may contextualize a person and his/her development" ( $p$. 2). From the context of higher education, for example, a positive social milieu may provide opportunities, pathways, and means (e.g., the provision of resources) to assist students in their learning experiences. In a similar vein, negative perception of a social milieu would indicate that people at school, for example, are not friendly and/or not welcoming. An appropriate social milieu, we contend, is more susceptible to cultural diversity and/or individual differences. In their recent study using SEM techniques, Phan et al. (2019c) found that the concept of the social milieu positively influenced a student's personal self-efficacy for academic learning $(\beta=0.19, p<0.001)$ and his/her ability to relate to others socially $(\beta=0.50, p<0.001)$

Relating to others In their earlier study, which focused on the topic of student well-being, Van Damme et al. (2002) explored facets that would emphasize the importance of a student's ability to relate to others in the community - for example: a student's social relationship with his teachers, and the notion of "social integration in class" - that is, the student's perception of how others perceive him and how he gets on with others. In their recent research, likewise, Phan and his colleagues introduced a similar term known as relating to others (e.g., peers) (e.g., Phan, 2017a; Phan et al., 2019c). Relating to others (e.g., friends), in this sense, entails a person's perceived social relationship with his/her peers, friends, teachers, and others at school - for example, is it positive? In an earlier study that involved secondary school students, Phan (2017a) found that the concept of relating to others positively influenced a student's state of motivation for learning $(\beta=0.17, p<0.01)$ and his/her indication of "liking for school" experience $(\beta=0.24, p<0.001)$

Pathways and means In our recent research development of subjective well-being (e.g., Phan et al., 2016b, 2019d), we conceptualize a social-related concept, which we coined as pathways and means. This psychosocial concept is concerned with a student's perception of whether an institution is providing opportunities, pathways, means, etc., for effective learning. For example, does an institution provide relevant resources (e.g., IT equipment) that could assist the student in her comprehension of Geometry? Does a teacher go out of his way to assist the student in her time of academic needs? A negative perception, in contrast, would indicate that an institution does not provide opportunities and/or have relevant pathway and means to facilitate a student's growth. At the same time, of course, negative perception would suggest that there is limited, if any, provision of opportunities, etc., for personal growth. To date, of course, this focus of inquiry (i.e., the effect of pathways and means) is still in its stage of infancy, requiring further empirical research for validation

\section{Psychological processes}

Personal resolve Recently developed, Phan et al. (2018b, p. 415) defined personal resolve as "an individual's internal state of decisiveness and resolute to strive for optimal achievement best in an optimistic manner. This definition emphasizes the importance of determination to overcome any obstacles that may arise and reflects an internal state of desire and purposive act to achieve optimal best in a subject matter. In this analysis, the deliberate nature of personal resolve serves to facilitate and motivate an individual's quest to accomplish a course of action in a positive and decisive manner." This summarized definition, we contend, contends that personal resolve is closely aligned with a person's "situated mindset" to remain on task and unwavered, regardless of difficulties, etc. In this sense, we rationalize that a student's personal resolve is related to her state of mental fortitude. In a number of correlational studies, Phan and his colleagues have reported on the positive predictive effect of personal resolve (e.g., Phan et al., 2018b, Phan et al., 2019d; Phan and Ngu, 2021a). For example, in a study that involved secondary school students, Phan et al. (2018b) found that personal resolve positively influenced different levels of self-efficacy beliefs for academic learning (e.g., personal resolve $\rightarrow$ task-specific self-efficacy, $\beta=0.14, p<0.05$ )

Effective functioning In tandem with the concept of personal resolve, Phan et al. (2018b, p. 414) introduced the concept of effective functioning, which "reflects the importance of structured thinking and organized behavior that enable personal accomplishment in an efficient manner. Engaging in effective functioning, for example, may motivate a student to remain steadfast and adhere to an effective study plan, regardless of the fact that it may be boring. By doing so, this would enable the student to automate specific schemas in order to achieve optimal best outcomes in mathematics". This definition, we contend, recognizes a need for a person to demonstrate efficiency, organization, and a structured pattern in planning for the purpose of execution. Recently, adhering to this definition, we introduce a similar term, coined as "optimal efficiency" (Phan and Ngu, 2021b). Optimal efficiency, in this case, considers the important issue of cost-best analysis by which a person's mindset would focus on the accomplishment of optimal outcome (i.e., maximum of accomplishment) for the least amount of time, effort, and/or expenditure of resources. In terms of empirical research, there is modest evidence to affirm the potent effect of effective functioning (e.g., Phan et al., 2018; Phan et al., 2018b). For example, in a study that involved university students, Phan et al. (2018) found that effective functioning positively influenced a student's state of motivation for learning $(\beta=0.36, p<0.001)$ and her accomplishment of optimal best practice $(\beta=0.17, p<0.01)$

Academic striving Adhering to the focus of subjective well-being, which explores theoretical concepts such as "flourishing" (Diener et al., 2010; Huppert and So, 2013) and "personal thriving" (Su et al., 2014; Wiese et al., 2018). Phan et al. (2020e) introduced a concept termed as academic striving. Academic striving is defined as "a person's effortful attempt to seek out a realistic and/or an ambitious endeavor for accomplishment. .. within the context of academic learning, a student may strive to achieve an exceptional standing. Another student's striving may consist of his/her concerted attempt to seek entry into a Medical degree program. Academic striving then compels and motivates a person to persist a specific course of action to attain the projected goal" (p. 451). In this sense, from our point of view, a student's indication of personal striving to succeed academically reflects his freewill and aspiration to acquire growth, regardless of its achievability. Interestingly, according to Phan et al. (2020e), personal striving does not necessarily yield concrete and/or accomplishable outcomes. In their correlational study, for example, Phan et al. (2020e) found that academic striving positively influenced a student's motivation for learning $(\beta=0.22, p<0.01)$ as well as his effort expenditure $(\beta=0.27, p<0.01)$. In a recent non-experimental research, likewise, Phan and Ngu (2021a) found that academic striving directly predicted four comparable outcomes: actual best practice $(\beta=0.21$, $p<0.01)$, personal resolve $(\beta=0.43, p<0.001)$, effort expenditure $(\beta=0.21, p<0.01)$, and effective functioning $(\beta=0.45, p<0.001)$ 
TABLE 1 | (Continued)

\begin{tabular}{|c|c|}
\hline Measured Indicator & Definition \\
\hline & Motivation \\
\hline Interest in learning & $\begin{array}{l}\text { In their study of subjective well-being, Van Damme et al. (2002) identified the concept of interest in learning, which seeks to understand } \\
\text { the nature of academic engagement in schoolwork (De Fraine et al., 2005; Van De Gaer et al., 2009b). Indeed, from their LOSO } \\
\text { questionnaire, items such as "I enjoy doing most of the subjects in this school," "I think that most of the subjects we are taught are very } \\
\text { worthwhile," and "I am really interested in most of the subjects" reflect the nature of intrinsic motivation and perceived value for learning. } \\
\text { A high indication of interest in learning, as a distinctive construct, would reflect a student's high level of motivation. In contrast, of } \\
\text { course, a low level of interest would suggest a low level of motivation. In recent years, using Van Damme et al.'s (2002) subscale, Phan } \\
\text { and Ngu (2018a) found that interest in learning tasks positively influenced different types of adaptive outcomes - for example: academic } \\
\text { grade }(\beta=0.46, p<0.001)\end{array}$ \\
\hline Motivation toward learning & $\begin{array}{l}\text { Aside from interest in learning, Van Damme et al. (2002) also introduced another concept, which is known as motivation toward } \\
\text { learning. The authors' line of inquiry (e.g., Van Damme et al., 2002; Van De Gaer et al., 2009a) with reference to this concept explores } \\
\text { the nature of a student's level of motivation toward her academic learning - for example, does the student show an appropriate level of } \\
\text { motivation or, alternatively, is there a lack of motivation toward commitment? Responses to items such as "There are few subjects for } \\
\text { which I really do my best," "I think that I rarely do my best at school," and "I really do my best at school," in this sense, indicate evidence } \\
\text { of a student's state of motivation. This motivation, of course, can be intrinsic or extrinsic. Similar to the concept of interest in learning, } \\
\text { there have been research undertakings that focus on the nature of motivation toward learning (e.g., Phan, } 2017 \mathrm{a} \text {; Phan et al., } 2018 \text {; } \\
\text { Phan et al., 2019d). For example, in a recent study that involved university students, Phan et al. (2019d) found motivation toward } \\
\text { learning to exert differing effects on different types of adaptive outcomes - social relationship with others }(\beta=0.50, p<0.001) \text {, personal } \\
\text { well-being }(\beta=0.13, p<0.05) \text {, personal resolve }(\beta=0.51, p<0.001) \text {, etc }\end{array}$ \\
\hline Self-efficacy & $\begin{array}{l}\text { Personal self-efficacy, situated within social cognitive theory (Bandura, 1997), is defined as "beliefs in one's capabilities to organize and } \\
\text { execute the courses of action required to produce given attainments" (p. 3). Personal belief of efficacy for academic learning, in this } \\
\text { case, is not concerned with a person's actual capability, but rather whether she has the perceived competence to complete an } \\
\text { undertaking. The potent effect of self-efficacy, according to Bandura (1997), is that it helps to mobilize a person's effort expenditure, as } \\
\text { well as to govern his affective responses and self-regulatory processes. For example, an efficacious student is more likely to persist and } \\
\text { to expend more effort into his schoolwork. Inefficacy, in contrast, is likely to yield detrimental consequences (e.g., undermine a student's } \\
\text { academic performance in a subject matter). There have been extensive research studies, spanning the course of four decades that } \\
\text { focused on the nature of self-efficacy within both academic and non-academic settings (e.g., Pajares and Miller, 1994; Schunk, 1995; } \\
\text { Pajares et al., 2000; Schunk and Meece, 2006; Liem et al., 2008; Phan et al., 2019d). Consistent and clear in terms of evidence, we } \\
\text { note that a heightened state of self-efficacy serves to improve academic performance }\end{array}$ \\
\hline
\end{tabular}

\section{Adaptive Outcomes}

Current best practice In his seminal review paper of subjective well-being, focusing on the process of optimization Fraillon (2004) introduced two terms: actual best practice and notional best practice. This introduction led Phan and his colleagues (e.g., Phan et al., 2016c, 2020b; Phan et al., 2018) to expand on this theorization - for example:

- Current best practice, denoted as $L_{1}$, according to Fraillon (2004) and Phan et al. (2019d), is defined as a person's perceived level of functioning at the present time - for example, "what is it that I am capable of at present in Algebra?" (e.g., I am able to solve equations with one unknown, $x$, at present). This example explains current best practice in terms of cognitive functioning

- Optimal best practice, denoted as $L_{2}$, in contrast, is defined as a person's perceived maximum level of functioning that could be fulfilled and/or accomplished (Fraillon, 2004; Phan et al., 2019d) - for example, "I perceive and believe that I am capable of accomplishing.... in Algebra" (e.g., I am capable of solving equations with three unknowns, $x, y$, and $z$. This accomplishment is my maximum capability). This example explains optimal best practice in terms of cognitive functioning

The study of best practice, theoretically, empirically, and methodologically, is interesting as it may contribute to the field of positive psychology (Csíkszentmihályi, 1990; Seligman, 1999; Seligman and Csíkszentmihályi, 2000)

Optimal Best Practice

The study of best practice within the context of academic learning "is concerned with a person's accomplishment of three distinctive areas of personal agency: acquired knowledge, personal experience, and personal functioning" (Ngu et al., 2019, p. 82). A person's "optimal best practice," in this case, is related to the maximization of his/her acquired knowledge, experience, and/or personal state of flourishing (e.g., feeling good about oneself). Indeed, optimal best practice, denoted as $\mathrm{L}_{2}$, and equivalent to notional best practice (Fraillon, 2004), is an interesting theoretical concept that may indicate a person's state of motivation, as well as her future performance outcomes. In their recent empirical study, Phan et al. (2019d) provided a conceptualization that depicted the association between current best practice and optimal best practice

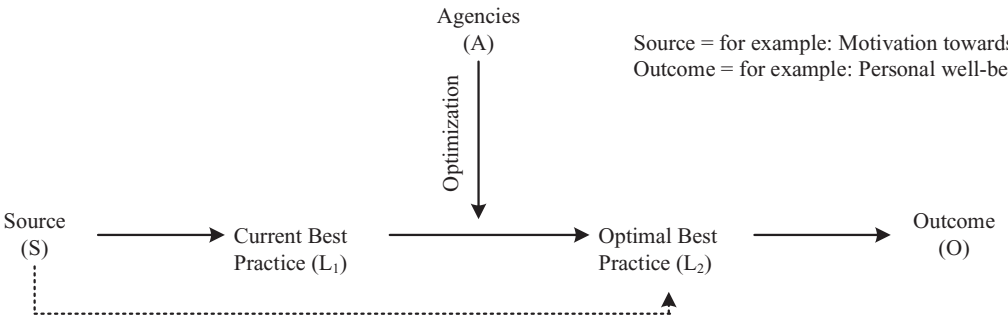


TABLE 1 | (Continued)

\begin{tabular}{|c|c|}
\hline Measured Indicator & Definition \\
\hline & Adaptive Outcomes \\
\hline & $\begin{array}{l}\text { From their research involving university students, for example, Phan et al. ( } 2019 \mathrm{~d}) \text { found that motivation toward learning positively } \\
\text { influence current best practice }(\beta=0.56, p<0.001) \text { and this level of best practice, in turn, predicted optimal best practice }(\beta=0.25 \text {, } \\
p<0.001) \text {. Optimal best practice, interestingly, exerted a positive effect on personal well-being }(\beta=0.28, p<0.01) \text {. In a recent study } \\
\text { that consisted of secondary school students, likewise, Phan and Ngu (2021a) found that both current best practice }(\beta=0.33, p<0.01) \\
\text { and personal resolve }(\beta=0.17, p<0.01) \text { positively predicted optimal best practice }\end{array}$ \\
\hline Academic Liking Experience & $\begin{array}{l}\text { The study of subjective well-being (Fraillon, 2004; Acu and Erebus International, 2008; Nsw Department of Education and Communities, } \\
\text { 2015) is detailed, suggesting that this concept quite diverse in terms of scope and coverage. What is subjective well-being in school } \\
\text { contexts? This is a question that Fraillon (2004) attempted to address in his comprehensive review of the subject matter. Van Damme } \\
\text { et al.'s (2002) article, likewise, referred to different facets that could espouse and define the concept of subjective well-being. A few } \\
\text { years back, Phan and his colleagues introduced a concept, which the authors termed as academic liking experience or, alternatively, } \\
\text { school experience (Phan, 2017a; Phan et al., 2018, 2019c). It was rationalized at the time that academic liking experience could, in part, } \\
\text { reflect a student's personal well-being at school. Does a student enjoy attending school, or would she prefer to stay at home and do } \\
\text { something else (e.g., play computer games)? How does she feel attending classes? Hence, these questions led Phan and his } \\
\text { colleagues to rationalize the possibility that academic liking experience would intricately relate to three main facets: emotions (e.g., "I feel } \\
\text { happy when I am school"), feelings (e.g., "I feel safe at school"), and preference (e.g., "I would rather stay at home than go to school") of } \\
\text { school. A high response score, in this case, would indicate and reflect positive schooling experiences (Phan, } 2017 \mathrm{a}) . \text { In a recent } \\
\text { correlational study that involved university students, we found that academic liking experience exerted a positive effect on emotional } \\
\text { well-being ( } \beta=0.26, p<0.001) \text { (Phan et al., 2019c) }\end{array}$ \\
\hline
\end{tabular}

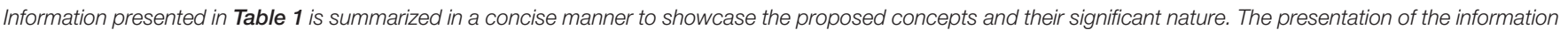
is not intended to provide comprehensive understanding, especially in terms of coherence and conceptualization.

of evidence, positive perceptions of social experiences (e.g., a friend's willingness to assist) could help to instill motivation for academic learning, whereas negative perceptions (e.g., a student's perceived sense that she is not being accepted by other students) would demotivate and serve to weaken one's resolve to engage.

There is also existing research development, which contends the potent influences of different aspects of perceived social experiences on different sub-psychological processes. For example, in a correlational study that focused on academic engagement, Liem and Martin (2011) found that peer relationships (e.g., opposite-sex relationship at school) positively predicted general self-esteem. In a study that consisted of children with dyslexia, Shehu et al. (2015) found a positive association between social relationships and self-esteem. In one of the earlier studies in the late 1990s, Wentzel (1998, p. 202) using multiple regression analysis reported some interesting patterns: peer support was a positive predictor of prosocial goal pursuit, teacher support was a positive predictor of both types of interest and of social responsibility goal pursuit, and parent support was a positive predictor of school-related interest and goal orientations. More recently, as indicated in Table 1, Phan and his colleagues observed the positive effects of perceived social experiences - for example: the effect of relating to others on personal striving (Phan et al., 2019d), the effect of the social milieu on self-efficacy (Phan et al., 2019c), and the effect of peer-peer social relationship on personal striving (Phan and Ngu, 2020a).

Analysis of existing research suggests then that there is clear and consistent evidence, which affirms the central role of perceived social experiences as an antecedent of different types of adaptive outcomes (Wentzel, 1998; Roseth et al., 2008; Umberson and Montez, 2010; Raufelder et al., 2013; Shehu et al., 2015). This proposition is poignant as it emphasizes the explanatory nature of perceived social experiences, which have both positive or negative connotations - for example: I feel that this school is not supporting me at all and that, importantly, people here are not too "welcoming" (i.e., this is a negative perception of social experience). A positive social experience, in this analysis, is more potent as it would help students cope with their academic learning, seek emotional and/or social support, and develop enriched well-being experiences (e.g., positive emotional well-being). By the same token, of course, there is credence to contend that a person's perceived social experiences are intricately linked to his/her sub-psychological processes for effective learning (e.g., a person's self-belief). In the context of the present study, we postulate that perceived positive social experiences in educational contexts (e.g., the perception that there are opportunities and pathways for personal growth) would positively influence different types of psychological and educational variables.

\section{The Importance of Psychological Processes}

One notable outcome of perceived positive social experiences is the enactment of internal psychological processes, $\xi_{2}$, which espouse three comparable sub-processes: personal resolve $\left(\mathrm{X}_{1}\right)$, effective functioning $\left(\mathrm{X}_{2}\right)$, and academic striving $\left(\mathrm{X}_{3}\right)$. This proposed psychological processes concept, from our conceptualization, coincides with the paradigm of positive psychology (Seligman and Csíkszentmihályi, 2000; Seligman et al., 2009; Seligman, 2010), which focuses on the notion of "positivity and proactivity" of human agency. One notable distinction of positive psychology, in particular, relates to the understanding that there are sub-psychological processes (e.g., a state of resilience) that may facilitate a person's state of functioning. For example, within the context of academic learning, there is evidence to indicate the positive effects of positive psychological 
sub-processes such as a state of buoyancy (Martin et al., 2013; Collie et al., 2015).

Our conceptualization considers three comparable constructs, which could potentially optimize a person's state of cognitive functioning: personal resolve, effective functioning, and academic striving. An analysis of the information detailed in Table 1 suggests that, in general, personal resolve, effective functioning, and academic striving are similar in terms of their nature and characteristics. One notable distinction in similarity lies in the facilitation and enhancement of a person's positive state of functioning, such as his/her achievement of optimal best in an academic subject matter (Fraillon, 2004; Martin, 2006; Phan et al., 2016c). For example, research development has noted consistent evidence, which shows the positive effect of personal resolve on the achievement of optimal best (Phan et al., 2019d; Phan and Ngu, 2021a). This line of empirical validation contends that a state of decisiveness and unwavered focus without any uncertainty is likely to associate with and/or instill a perceived of confidence, resulting in a person's self-determination and subsequent performance outcome. Indecisiveness, in contrast, is more aligned with a person's sub-optimal experiences, reflecting in his/her underachievement in a subject matter.

Examining the nature of sub-psychological processes of personal resolve, effective functioning, and academic striving, which may operate in tandem with each other, is insightful as this would provide clarity into their combined and/or individual predictive effects on different types of adaptive outcomes. Specifically, as shown in Figure 1, it is plausible to consider two contrasting explanatory and predictive effects: the predictive effect of the latent representation of psychological processes on an adaptive outcome [i.e., $\xi_{2} \rightarrow$ O, where $\xi_{2}=$ psychological processes, $\mathrm{O}=$ adaptive outcome (e.g., a state of motivation), $\rightarrow=$ predictive effect $]$ versus the predictive effects of the three measured indicators on the same adaptive outcome [e.g., $\mathrm{X}_{1} \rightarrow$ $\mathrm{O}$, where $\mathrm{X}_{1}=$ personal resolve, $\mathrm{O}=$ adaptive outcome (e.g., a state of motivation), $\rightarrow=$ predictive effect]. This consideration, we contend, reflects methodological innovation, providing a basis for us to gauge into comparative predictive effects of psychological processes. By the same token, structurally, it is also possible for us to test and identify different types of information, which could assist to account for the formulation of personal resolve, effective functioning. For example, in a recent study that involved university students, Phan et al. (2018) found that a student's current level of knowledge and understanding of a subject matter, termed as "realistic best practice," would positively influence a state of effective functioning and his/her personal resolve. Interestingly, with secondary school students, Phan and $\mathrm{Ngu}$ (2020a) noted that the formulation of academic striving, defined as a person's effortful attempt to seek out a realistic and/or an ambitious endeavor for accomplishment, is shaped by different psychosocial factors - academic self-efficacy, global selfesteem, peer-peer social relationship, personal well-being, and belief of optimal best.

\section{The Importance of Motivational Beliefs}

Another potential outcome of perceived positive social experiences, and also that of the enactment of psychological processes, is a perceived state of motivation (Franken, 2007). The study of motivation within the field of Educational Psychology is extensive, with different theoretical perspectives offered and research inquired undertaken. Maslow $(1968,1970)$ humanistic theory of motivation, for example, focuses on a person's motive to achieve self-fulfillment of different needs (e.g., a need to selffulfill and experience of love), whereas the cognitive perspective of motivation focuses on theoretical understanding of attribution (e.g., attribution of success that reflects one's own personal ability) (Weiner, 1972, 1986), self-determination (Deci and Ryan, 1991, 2008), and value-expectancy beliefs (Eccles et al., 1983; Wigfield and Eccles, 2000). Researchers and educators have over the years proposed different inquiries for research development, focusing on antecedents and consequences of a state of motivation and, likewise, a state of demotivation. Research undertakings into the complex nature of motivation (Sansone and Harackiewicz, 2000; Pintrich and Schunk, 2002; Franken, 2007; Schunk et al., 2008) are effective and beneficial, providing theoretical insights and fruitful information for the purpose of practicality - for example, what is the most effective strategy to instill extrinsic motivation?

Our conceptualization of motivation, $\xi_{3}$, as a distinct construct, depicts three comparable and interrelated constructs, interest in learning $\left(\mathrm{X}_{1}\right)$, motivation toward learning $\left(\mathrm{X}_{2}\right)$, and self-efficacy for learning $\left(\mathrm{X}_{3}\right)$. The stipulation of $\mathrm{X}_{1}, \mathrm{X}_{2}$, and $\mathrm{X}_{3}$, in this case, enables us to provide a definition of motivation, which we consider it as being "a multifaceted and positive entity that encompasses one's personal interest and a heightened state of self-belief to accomplish enriched learning experiences for different types of intrinsic reasons". This consideration, for us conceptually, contends that the nature of motivation is intrinsic, wherein a person's intent and purposive act is to learn and accomplish for intrinsic reasons, such as enjoyment, fulfillment of an inner desire to achieve mastery, and to improve personal self-belief of competence. From our proposition then, a person's low level of interest and motivation, as well as his/her inefficacy for academic learning (i.e., a weakened state of self-efficacy) would undermine, weaken, and result in underperformance in a subject matter. Self-efficacy and high levels of interest and motivation, in contrast, would improve and/or facilitate a student's learning experience.

There is a plethora of research that has yielded clear and consistent evidence, highlighting the potent role of motivation as a facilitator and predictor of different types of adaptive outcomes (Pintrich and Schunk, 2002; Franken, 2007; Schunk et al., 2008). What is innovative and relatively unique about our conceptualization, however, relates to the stipulation of contrasting predictive effects of both latent factor (i.e., $\xi_{3}$ $\rightarrow \mathrm{O}$, where $\xi_{3}=$ motivation, $\mathrm{O}=$ adaptive outcome, $\rightarrow=$ predictive effect) and measured indicators of motivation (e.g., $\mathrm{X}_{1} \rightarrow \mathrm{O}$, where $\mathrm{X}_{1}=$ interest in learning, $\mathrm{O}=$ adaptive outcome, $\rightarrow=$ predictive effect) on different types of adaptive outcomes. For example, evidence of a positive effect of selfefficacy on achievement of an adaptive outcome would provide theoretical insights into the development of a teaching strategy and/or an educational program that could enhance and foster 
motivation, resulting improved academic performances and enriched learning experiences.

Our conceptualization also allows us to examine different types of antecedents that could account for the formulation of motivation, in general. What causes a student to feel motivated to engage in a particular course of action, academically and/or non-academically? In relation to self-efficacy (Bandura, 1997), for example, a number of correlational studies have attested to the effect of enactive learning experience such as successful accomplishments (Lent et al., 1991; Pajares et al., 2007; Liem et al., 2008; Usher and Pajares, 2008). In a similar vein, existing research has found numerous factors that could influence a person's interest for learning and proactive engagement (Senko and Miles, 2008; Upadyaya et al., 2011; Walkington, 2013). We contend, as shown in Figure 1, that the two latent variables of perceived social experiences, $\xi_{1}$, and psychological processes, $\xi_{2}$, and their respective measured indicators could influence motivation and its respective measured indicators.

\section{ACCOMPLISHMENT OF ADAPTIVE OUTCOMES}

Focusing on achieving and/or experiencing different types of adaptive outcomes in school contexts is more inclusive than the notion of "academic achievement." Academic achievement, we contend, is relatively restricted, limiting to the seeking of understanding of a student's academic learning and his/her accomplishment of learning outcomes. More recently, educators and researchers have advocated for the development of holistic education (Forbes, 2003; Hare, 2010), which focuses on the "totality" of a student's schooling experiences - for example, cognition, social relationship, moral development, etc. Holistic education, in this sense, espouses the important viewpoint that educational successes do not simply mean and/or entail high academic grades, but rather encompass a myriad of school-based experiences (e.g., sound social development, and/or the fostering of emotional well-being) (Phan and Ngu, 2019a).

In terms of the present study, we conceptualize the concept of adaptive outcomes as a distinct latent factor, $\xi_{4}$, which consists of three corresponding measured indicators: a student's current best practice (i.e., what a student is capable of at present - for example: "I am able to understand and solve equations with one unknown, $x$, at present") $\left(\mathrm{X}_{1}\right)$ and optimal best practice (i.e., what a student perceives his/her maximum capability to be - for example: "I perceive that I am capable of solving equations with three unknowns, $x, y$, and $\left.z^{\prime \prime}\right)\left(\mathrm{X}_{2}\right)$ in a subject matter (Fraillon, 2004), as well as his/her perceived "academic liking experience" $\left(X_{3}\right)$ (Van Damme et al., 2002). This conceptualization of adaptive outcomes, we contend, is innovative as it does not place emphasis on actual test scores and/or academic grades, hence, helping to negate the academic pressure of a student having to perform well academically. Moreover, from our point of view, the inclusion of best practice is significant as it reflects recent development into the study of optimal best (Fraillon, 2004; Liem et al., 2012; Phan et al., 2019d; Phan and Ngu, 2021a). Optimal best is a positive concept, emphasizing a person's state of flourishing or flourished experience in a subject matter. Indication of optimal best, aided by current best practice, entails the maximization in a person's state of functioning (e.g., a person's maximized state of cognitive functioning at the present time). On this basis, a person's achievement of adaptive outcomes would showcase his/her positive academic liking experience (e.g., "I enjoy attending school"), as well as high levels of current and optimal best practice in a subject matter.

Aside from empirical evidence from existing research undertakings, we also use the theoretical paradigm of philosophical psychology (Thagard, 2014, 2018; Phan et al., 2020d) to assist us with our development of a conceptual framework for investigation. This theoretical paradigm reflects and entails the reliance and use of personal intuition, logical reasoning, philosophical understanding, and previous research development to conceptualize new ideas and viewpoints. For example, our recent research focus on the subject of life and death education (Chen, 2012, 2017; Huang, 2014) led to our use of philosophical reasoning and the proposed concept of “esoteric psychology" (Phan et al., 2020d, 2021c). In a similar manner, in tandem with extensive research studies reviewed so far, we use philosophical psychology as a basis to assist us with our conceptualization, which connotes the potency of three comparable direct effects on students' adaptive outcomes, $\xi_{4}$ : perceived social experiences, $\xi_{1}$, psychological processes of effective learning, $\xi_{2}$, and motivational belief, $\xi_{3}$. Philosophically, in this sense, a question that we could ask is whether there is credence to argue that $\xi_{1}, \xi_{2}$, and $\xi_{3}$ would positively influence $\xi_{4}$ ? At the same time, however, it is plausible for us to consider the direct predictive effects of the measured indicators of $\xi_{1}, \xi_{2}$, and $\xi_{3}$ on $\xi_{4}$ - for example: perception of the social milieu $\rightarrow$ adaptive outcomes versus personal resolve $\rightarrow$ adaptive outcomes. It is also likely that $\xi_{1}, \xi_{2}$, and $\xi_{3}$ and their respective measured indicators could predict the three measured indicators of $\xi_{4}$ for example: perceived social experiences, $\xi_{1}, \rightarrow$ current best practice versus perception of the social milieu $\rightarrow$ current best practice. Overall, our proposition for examination is insightful and could potentially provide valuable information for guidance, especially in terms of design and development of pedagogical practices, learning objectives, etc., that would enhance and improve different types of adaptive outcomes.

\section{SIGNIFICANCE OF THE PRESENT STUDY}

Overall, then, the preceding sections have provided a rationalization of a conceptualization, which depicts a number of relationships for investigation. As shown in Figure $\mathbf{1}$ and Table 2, the significance of our research proposition lies in our attempt to test a structural model that places emphasis on two types of predictive relationship: predictive effects of latent factors and predictive effects of measured indicators. This consideration into two distinct "levels" or types of prediction is interesting, especially from a methodological point of view. Our conceptualization coincides with the nature of the paradigm of positive psychology (Seligman and Csíkszentmihályi, 2000; 
TABLE 2 | Latent theoretical concepts, definitions, and measured indicators.

\begin{tabular}{|c|c|c|}
\hline Latent theoretical concepts & Our definition & Measure indicators \\
\hline Perceived social experiences & $\begin{array}{l}\text { A present perception (i.e., positive versus negative) of the myriad of } \\
\text { different social experiences that a student may have at school or in } \\
\text { university }\end{array}$ & $\begin{array}{l}\text { - The Social Milieu } \\
\text { - Relating to others } \\
\text { - Pathways and means }\end{array}$ \\
\hline Psychological processes & $\begin{array}{l}\text { A student's continuing frame of mind to focus on disposition toward } \\
\text { strong resolute, structured thoughts and organization, and } \\
\text { aspiration to strive for educational success }\end{array}$ & $\begin{array}{l}\text { - Personal resolve } \\
\text { - Effective functioning } \\
\text { - Academic striving }\end{array}$ \\
\hline Motivation & $\begin{array}{l}\text { Motivation is multifaceted, global, and positive, encompassing } \\
\text { personal interest and a heightened state of self-belief to accomplish } \\
\text { enriched learning experiences for intrinsic reasons }\end{array}$ & $\begin{array}{l}\text { - Interest in learning } \\
\text { - Motivation toward learning } \\
\text { - Self-efficacy }\end{array}$ \\
\hline Adaptive outcomes & $\begin{array}{l}\text { A person's academic experience at school or in university (i.e., } \\
\text { positive versus negative), as well as his indication of achievement of } \\
\text { best practice in different subject matters }\end{array}$ & $\begin{array}{l}\text { - Current best practice } \\
\text { - Optimal best practice } \\
\text { - Academic liking experience }\end{array}$ \\
\hline
\end{tabular}

Seligman et al., 2009; Seligman, 2010), and reflects the positivity and proactivity of human agency - for example, academically, we postulate that positive psychological processes could predict and/or explain a student's achievement and experience of optimal best in a subject matter. This focus into the proactivity and fostering of adaptive outcomes (e.g., a focus on optimal best) is different from the study of the negative or deficit nature of the schooling processes (e.g., a focus on school disengagement) (Liem et al., 2008; Tam, 2011; Henry et al., 2012), which would require remedy and the use of preventive measures to counter such discourse (e.g., how to prevent and negate negative schooling experiences). We contend that our proposed inquiry is significant as it highlights the potential interrelations between three distinct theoretical orientations (i.e., perceived social experiences versus psychological processes versus motivational beliefs), which then could account for a student's adaptive outcomes.

\section{MATERIALS AND METHODS}

\section{Sample and Procedure}

Seven hundred and thirty-nine undergraduate students $(N=442$ women, 297 men) from three private universities in Taiwan participated in this study. The dataset, collected in 2019, forms part of our larger research project, involving secondary and university students from Australia, Malaysia, and Taiwan. The study reported in this manuscript was approved by the University of New England Research Ethics Committee. Because of the fact that the participants were all adults (i.e., over the age of 18), we decided to use a simpler approach for recruitment, which the university approved - that is, to verbally seek permission at the onset and anyone who did not want to take part to inform us. This method of verbally seeking participatory consent, used by us on previous research undertakings, is more convenient logistically.

Our sampling was convenient as it was logistically difficult to seek permission from students in other universities and colleges to take part in the present research study. Aside from this difficulty, limited resources also deterred us from attempting to expand on our data collection. The participants voluntarily took part in the study, knowing that there were no incentives. We administered the questionnaires in class, using the traditional paper-format. Overall, answering the Likert-scale measures took approximately 35-40 $\mathrm{min}$ to complete. The front page of the questionnaires contained demographic information - for example, which university a student attended, and what degree program he/she was studying. Overall, all the participants were full-time students and came from 40 different departments across the three universities.

The medium of formal instruction at school and in university in Taiwan is Chinese Mandarin. In 2016, we translated the questionnaires from English to Chinese Mandarin using a three-step methodological procedure: (i) Step 1: to translate the questionnaires from English to Chinese Mandarin $\left(\mathrm{E}_{1} \rightarrow\right.$ $\mathrm{CM}_{1}$ ), (ii) Step 2: to translate the translated questionnaires from Chinese Mandarin to English $\left(\mathrm{CM}_{1} \rightarrow \mathrm{E}_{2}\right)$, and (iii) Step 3: compare the original English version of the questionnaires (i.e., $E_{1}$ ) with the translated version (i.e., $E_{2}$ ) (e.g., see Phan et al., 2019d for an in-depth description:). We have since then used the questionnaires with different cohorts, and results published (Phan et al., 2019c,d, 2020e) show sound psychometric properties (e.g., factorial structures).

\section{Instruments}

Overall, from the preceding sections, there are 12 variables, which involved the use of 12 corresponding subscales, measured on a Likert-scale with five ratings - for example: 1 (Complete Not True), 2 (Not True), 3 (Neutral), 4 (True), and 5 (Completely True).

\section{The Social Milieu}

The Social Milieu Subscale (Phan and Ngu, 2016a; Phan et al., 2019c), consisting of five items - for example: "I find this university is very welcoming" and "This university is very accepting of people from other cultures." Cronbach's alpha value for the subscale upon examination was 0.77 .

\section{Relating to Others}

We (e.g., Phan et al., 2019c) recently adapted the LOSO Questionnaire (Van Damme et al., 2002) and developed five items to measure and assess the concept of relating to others - for example: "I find it easy to relate to others (e.g., lecturers) at university" and "I find often it difficult to express my feelings to 
others (e.g., peers) at university." Cronbach's alpha value for the subscale upon examination was 0.74 .

\section{Pathways and Means}

For consistency, awhile back, we developed five items to measure and assess the concept of pathways and means (Phan and Ngu, 2014). To date, we have not had an opportunity to use this subscale. The items included, for example: "I want to explore different options that are available to help me with my studies" and "I accept any help (e.g., utilization of resources) that is available to help with my studies." Cronbach's alpha value for the subscale upon examination was 0.76 .

\section{Personal Resolve}

We adapted five items from recent research (Phan et al., 2018b, Phan et al., 2019d) to measure and assess the concept of personal resolve, which include, for example: "I will do whatever it takes to master my academic studies at university" and "I have a strong desire to succeed in my academic studies at university." Cronbach's alpha value for the subscale upon examination was 0.83 .

\section{Effective Functioning}

We adapted five items from recent research (Phan et al., 2018; Phan et al., 2018b) to measure and assess the concept of effective functioning, which included, for example: "I have been told at university that I am quite efficient" and "I always keep to my routine when studying at university." Cronbach's alpha value for the subscale upon examination was 0.70 .

\section{Academic Striving}

We developed five items to measure and assess the concept of academic striving, which included, for example: "I always strive to achieve good academic results at university" and "I see very little point in achieving high results at university." Cronbach's alpha value for the subscale upon examination was 0.77 . Interestingly, with another cohort of university students in 2017, and recently published (Phan et al., 2020e), we achieved a reliability estimate of 0.78 for this subscale.

\section{Interest in Learning Tasks}

We adapted and used five items from the LOSO Questionnaire (Van Damme et al., 2002) to measure and assess the concept of interest in learning tasks. The items included, for example: "I enjoy learning the different subjects in this university" and "I believe many things we learn in university are not important." Cronbach's alpha value for the subscale upon examination was 0.81 .

\section{Motivation Toward Learning}

We adapted and used five items from the LOSO Questionnaire (Van Damme et al., 2002) to measure and assess the concept of motivation toward academic learning. The items included, for example: "I can do much better for some academic subjects at university than I do now" and "I rarely do my best at university." Cronbach's alpha value for the subscale upon examination was 0.79 .

\section{Personal Belief of Efficacy for Learning}

We adapted five items from the Motivated Strategies for Learning Questionnaire (Pintrich et al., 1991, 1993) to measure and assess the concept of personal belief of efficacy for academic learning. The items included, for example: "I believe I will receive excellent grades in classes at this university" and "I expect to do well academically in my classes for different subjects (e.g., Psychology)." Cronbach's alpha value for the subscale upon examination was 0.82 .

\section{Current Best Practice}

From theorization of best practice (e.g., Fraillon, 2004; Phan et al., 2018), we revised our original subscale, known as the Optimal Outcomes Questionnaire (Phan et al., 2015), which consisted of eight items, to a shorter version of five items - for example: "I am content with what I have accomplished so far at this university" and "I can achieve what is being asked of me at this university." Cronbach's alpha value for the subscale upon examination was 0.81 . Previous research studies reported similar reliability estimates (e.g., Phan et al., 2018).

\section{Optimal Best Practice}

Similar to current best practice, we revised our original subscale (Phan et al., 2015) so that the new version has five items - for example: "I can achieve much more at university than I have indicated through my work so far" and "I want to learn and do more at university." Cronbach's alpha value for the subscale upon examination was 0.73 .

\section{Academic Liking Experience}

We adapted the LOSO Questionnaire (Van Damme et al., 2002) and developed five items to measure and assess the concept of academic liking experience. The items included, for example: "I really like going to university" and "I would rather stay at home than to attend university" (Note: negative item). Cronbach's alpha value for the subscale upon examination was 0.84 .

\section{DATA ANALYSES}

Our data analyses, overall, consisted of two main stages: (i) a four-factorial structure using confirmatory factor analysis (CFA) techniques (Bollen, 1989; Kline, 2011), and (ii) a complete structural model to validate our original a priori model (Figure 1), using structural equation modeling (SEM) techniques (Bollen, 1989; Kline, 2011). Overall, the participants responded to a suite of 60 Likert-scale items, which we then formed composite scores for the 12 measured indicators. In other words, each measured indicator (e.g., the Social Milieu measured indicator, the Relating to others measured indicator, the Pathways and Means measured indicator, etc.) is a composite score of five individual item responses. In sum, from this calculation, we have: 12 measured indicators $\times 4$ latent factors (Note: each latent factor is defined by three measured indicators, and each measured indicator is made up of a composite score of five items - see Figure 2 for explanation. 


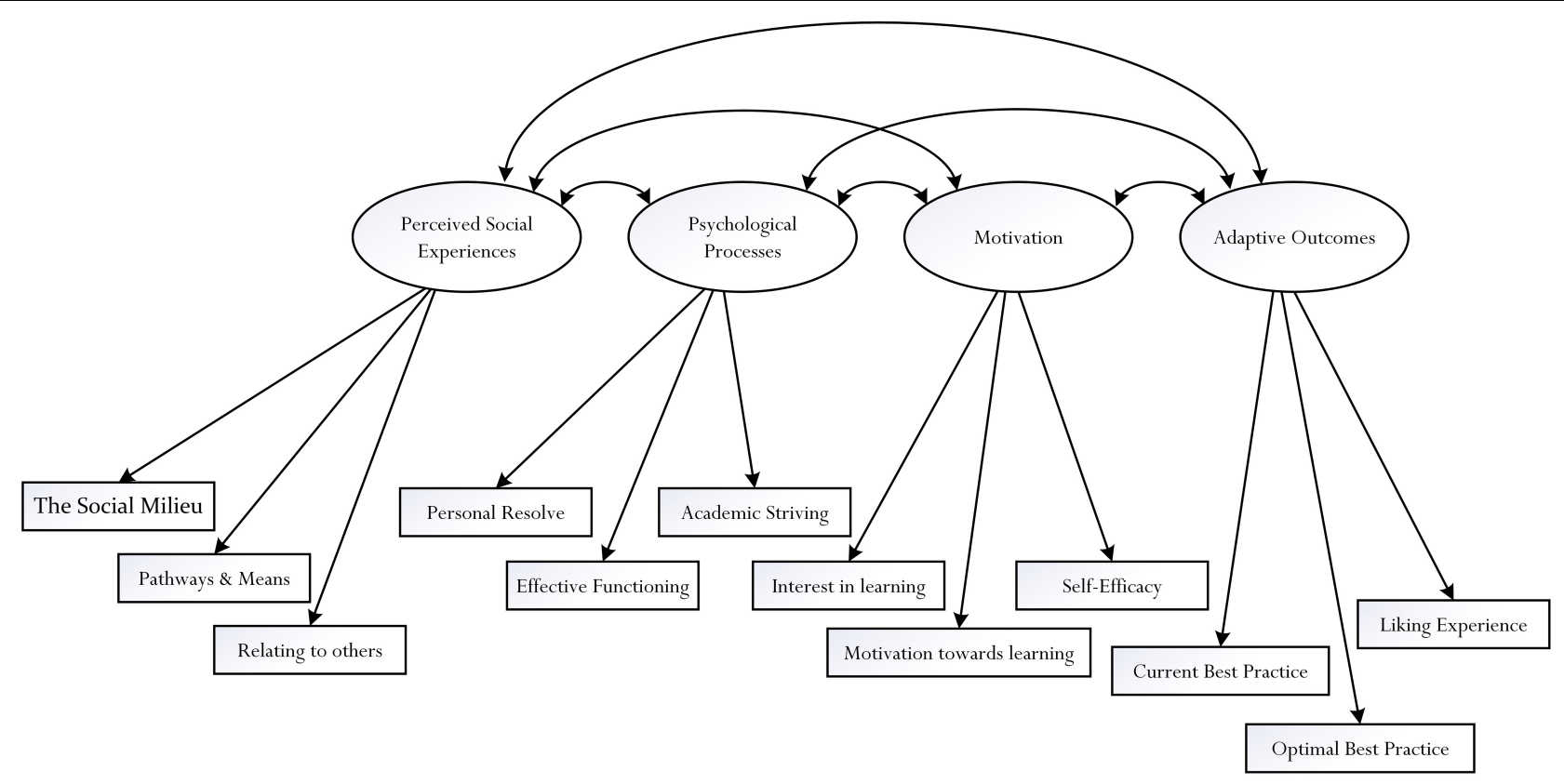

FIGURE 2 | Factorial structure of perceived social experiences, psychological experiences, motivation, and adaptive outcomes. Each measured indicator (e.g., the Social Milieu) is made of a composite score of responses from the five items.

\section{Confirmatory Factor Analysis}

A four-factorial structure is interesting and may, in this case, provide evidence of factor loadings and the potential interrelations between the four latent factors. We used the statistical software package MPlus 8.5 (Muthén and Muthén, 1998-2012) to assist with our analyses of a four-factor model. Likewise, SPSS 25 was used for descriptive statistics (e.g., data screening). Per guidance (Bollen, 1989; Kline, 2011), we performed an initial data screening test to ensure multivariate normality and the justification of using maximum likelihood (ML) estimates to test our hypothesized model [e.g., kurtosis values ranging from -0.06 (Academic Striving) to 1.02 (Optimal Best Practice), Std error $=0.18$; skewness values ranging from -0.61 (Current Best Practice) to 0.06 (Academic Striving), Std error $=0.09]$. From previous research undertakings (e.g., Green et al., 2012; Liem et al., 2012; Phan et al., 2019d), we considered the following indices to assist in the gauging of appropriate model fits: the Comparative Fit Index (CFI) (i.e., CFI value $>0.95$ ), the Tucker Lewis Index (TLI) (i.e., TLI value $>0.95$ ) the Root Mean Square Error of Approximation (RMSEA) (i.e., RMSEA value $<0.07$ ), the $\chi^{2}$ test statistic, and an evaluation of parameter estimates were used in the present research to assess model fit (Liem and Martin, 2011).

Correlations between mean scale scores are shown in Table 3. Our CFA undertaking for the four-factor model showed an appropriate model fit, as indicated by the following goodnessof-fit index values: $\mathrm{CFI}=0.94$, TLI $=0.92$, RMSEA $=0.08$, $p<0.001($ Lo90 $=0.071$, Hi90 $=0.090)$, and $\chi^{2} / \mathrm{d} f=5.77$. From Table 4, the factor loadings ranged from 0.52 to 0.77 for perceived social experiences, 0.70 to 0.75 for psychological processes, 0.63 to 0.70 for motivation, and 0.53 to 0.86 for adaptive outcomes, $p<0.001$. associations also existed between the four latent factors: $r=0.95, p<0.001$ for psychological processes and perceived social experiences, $r=0.92, p<0.001$ for motivation and perceived social experiences, $r=0.89, p<0.001$ for motivation and psychological processes, $r=0.77, p<0.001$ for adaptive outcomes and perceived social experiences, $r=0.82$, $p<0.001$ for adaptive outcomes and psychological processes, and $r=0.77, p<0.001$ for adaptive outcomes and motivation.

\section{Structural Equation Modeling}

The results established from the factorial structure analysis substantiated our SEM undertakings, which consisted of a baseline model. Overall, from the hypothesized a priori model shown in Figure 1, there are four latent factors (i.e., perceived social experiences, psychological processes, motivation, and adaptive outcomes) and 12 measured indicators. The baseline model, denoted as Model $\mathrm{M}_{0}$, consisted of six structural paths for statistical testing: the structural path from perceived social experiences to psychological processes, the structural path from psychological processes to motivation, the structural path from perceived social experiences to motivation, the structural path from motivation to adaptive outcomes, the structural path from psychological processes to adaptive outcomes, and the structural path from perceived social experiences to adaptive outcomes. The results of this base-line model, using covariance matrices as correlation matrix analysis is known to entail potential problems (e.g., producing incorrect goodness-of-fit index values (Byrne, 1998; Jöreskog and Sörbom, 2001) are relatively modest in terms of fit - for example: $\chi^{2} / \mathrm{d} f=5.77$, CFI $=0.94$, TLI $=0.92$, RMSEA $=0.080$. 


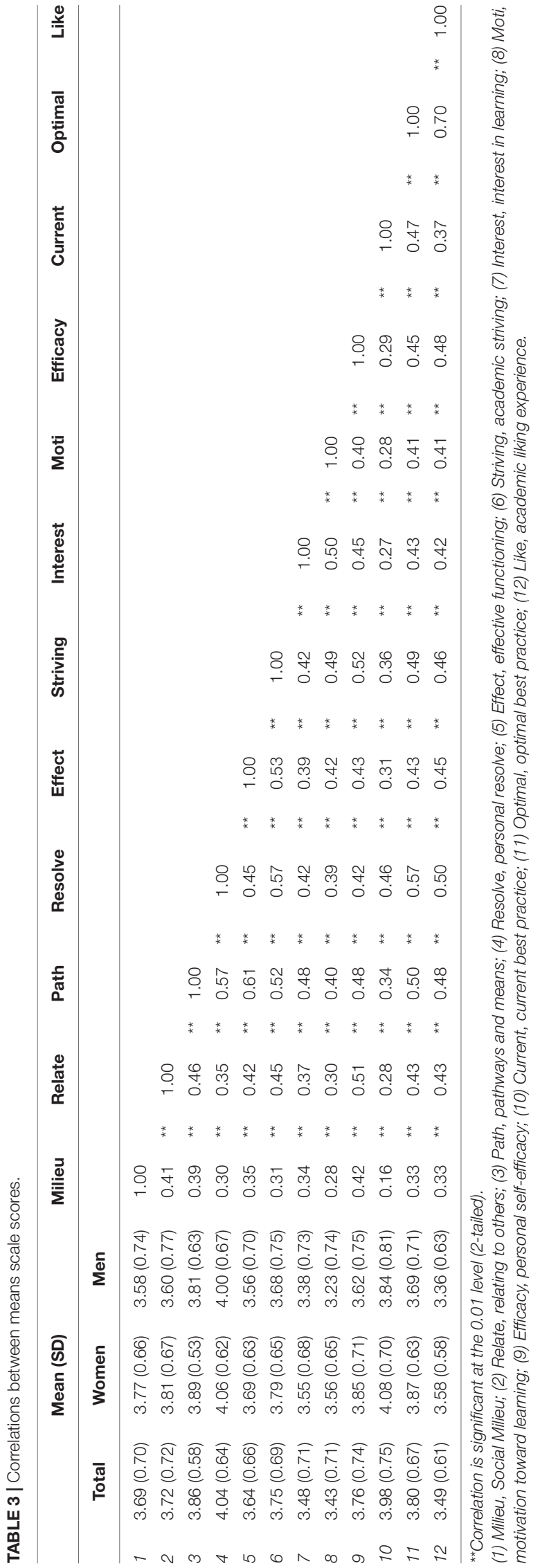

From a researcher's point of view, existing theorizations and research development (e.g., Schumacker and Lomax, 2004; Kline, 2011; Byrne, 2012) would recommend the finalization and discussion of the results of Model $\mathrm{M}_{0}$. Having said this, we are interested to test different iterations of Model $\mathrm{M}_{0}$, via modification fit indices.

We are interested, in this case, to explore the relationships between both latent factors and measured indicators. Statistical software packages such as MPlus 8.5 (Muthén and Muthén, 1998-2012) provide modification fit indices to assist a researcher in his/her quest to achieve an optimal fit for an a priori model. Having said this, researchers have cautioned the use of modification fit indices, contending that respecification of an a priori model depends on rationale and/or strong theoretical and/or empirical grounding (Byrne, 1998; Kline, 2011). Our testing and comparison of different a priori and a posteriori models is interesting, as it enables us to establish theoretical understanding into $\mathrm{L}_{1}$ (e.g., perceived social experiences $\rightarrow$ psychological processes) and $\mathrm{L}_{2}$ (e.g., relating to others $\rightarrow$ psychological processes) relationships. Table 5 shows the testing of seven a posteriori models. Goodness-of-fit index values are also provided to help finalize and determine the optimal fit model for discussion.

The respecification of a base-line model and, subsequently, a comparison of two competing models (e.g., Model $\mathrm{M}_{0}$ versus Model $\mathrm{M}_{1}$ ) require the use of the $\Delta \chi^{2}$ test, as well as an inspection of the goodness-of-fit index values. The principle of parsimony, in this case, advocates for the acceptance of a less restricted model. Overall, as shown in Table 5, the results (e.g., the use of the $\Delta \chi^{2}$ test as well as various goodness-of-fit index values) indicate a progression in improvement of model fit from Model $\mathrm{M}_{0}$ to Model $\mathrm{M}_{7}$. From the modification fit index values, we respecified Model $\mathrm{M}_{0}$ to include seven additional structural paths, which we freed one at a time:

(i) Model $M_{1}$ : the inclusion of the path from the measured indicator, pathway and means, to the measured indicator, effective functioning. This structural path $(\beta=0.33$, $p<0.001)$ places emphasis on the provision of opportunities, pathways, and means, which would encourage and/or compel a student to be more structured in his thinking, organization, and/or planning - for example, an educator informing to the class that there are limited resources available, requiring students to be more effective. This example is logical and suggests that, despite opportunities, pathways, and means, circumstances and personal situations made instill understanding of effective functioning.

(ii) Model $\mathrm{M}_{2}$ : the inclusion of the path from the measured indicator, relating to others, to the measured indicator, self-efficacy. This structural path $(\beta=0.20, p<0.001)$ substantiates Bandura (1997) social cognitive theory, placing emphasis on the use of vicarious information to instill a heightened state of self-efficacy. There is evidence, in this analysis, to support and affirm the importance of socially derived information (e.g., proactive peer social 
TABLE 4 | Factor loadings for a four-factor model.

\begin{tabular}{|c|c|c|c|c|}
\hline & Perceived Social Experiences & Psychological Processes & Motivation & Adaptive Outcomes \\
\hline Social Milieu & 0.52 & - & - & - \\
\hline Relating to others & 0.63 & - & - & - \\
\hline Pathways and means & 0.77 & - & - & - \\
\hline Personal resolve & - & 0.72 & - & - \\
\hline Effective functioning & - & 0.70 & - & - \\
\hline Academic striving & - & 0.75 & - & - \\
\hline Interest in learning & - & - & 0.67 & - \\
\hline Motivation toward learning & - & - & 0.63 & - \\
\hline Self-efficacy & - & - & 0.70 & - \\
\hline Current best practice & - & - & - & 0.53 \\
\hline Optimal best practice & - & - & - & 0.86 \\
\hline Academic liking experience & - & - & - & 0.81 \\
\hline
\end{tabular}

Factor loadings are statistically significant at $p<0.001$.

relationship in class) for the purpose of self-efficacy (Usher and Pajares, 2006; Phan, 2012).

(iii) Model $\mathrm{M}_{3}$ : the inclusion of the path from the measured indicator, personal resolve, to the latent factor, adaptive outcomes. This structural path $(\beta=0.28, p<0.001)$ is interesting, highlighting the $\mathrm{L}_{2} \rightarrow \mathrm{L}_{1}$ relationship. Moreover, evidence of this structural path supports recent development into the predictive and explanatory of personal resolve (e.g., Phan et al., 2018; Phan et al., 2020e), highlighting the importance of a person's state of unwavered concentration and decisiveness. A high level of personal resolve, in this analysis, may mobilize persistence and compel a student to expend more effort, resulting in accomplishment of different types of adaptive outcomes.

(iv) Model $\mathrm{M}_{4}$ : the inclusion of the path from the measured indicator, pathways and means, to the measured indicator, personal resolve. This structural path $(\beta=0.25, p<0.001)$ is significant, highlighting the significance of pathways and means - in this analysis, similar to that of effective functioning, the provision of opportunities, pathways, and means is beneficial, enabling a student to develop skills and experiences to be decisive in her academic studies. For example, opportunities to engage in complex learning tasks, and/or the use of encouraging and persuasive feedbacks may instill personal resolute to succeed.

(v) Model $\mathrm{M}_{5}$ : the inclusion of the path from the measured indicator, personal resolve, to the measured indicator, current best practice. This structural path $(\beta=0.22$, $p<0.001$ ), importantly, supports previous evidence that affirms the predictive nature of personal resolve (e.g., Phan et al., 2018; Phan et al., 2020e). Interestingly, however, the direct effect of personal resolve is insightful for the purpose of theoretical contribution to the nature of current best practice. For example, a state of resolute and decisiveness may play a poignant role in helping a student to make more accurate judgments and assessments of his/her existing capability (e.g., "This is what I am capable of at present").

(vi) Model $\mathrm{M}_{6}$ : the inclusion of the path from the measured indicator, self-efficacy, to the measured indicator, academic liking experience. This structural path $(\beta=0.12, p<0.01)$ support existing research development, which affirms the potent effect of personal self-efficacy for academic learning (e.g., Pajares and Miller, 1994; Bandura, 1997; Liem et al., 2008; Martin et al., 2010). A heightened state of selfefficacy, for example, is likely to mobilize various cognitive and non-cognitive processes (e.g., persistence in the face of difficulty), which would result in learning and other school-based accomplishments (e.g., academic buoyancy) (Martin et al., 2010).

(vii) Model $\mathrm{M}_{7}$ : the inclusion of the path from the measured indicator, academic striving, to the measured indicator, motivation toward learning. This structural path $(\beta=0.11$, $p<0.01)$ is significant, supporting recent research development into the predictive nature of the concept of academic striving (Phan et al., 2020e). Academic striving, based on the paradigm of positive psychology (Csíkszentmihályi, 1990; Seligman, 1999; Seligman and Csíkszentmihályi, 2000), is conceptualized as a positive and proactive concept (e.g., seeking to strive for a future endeavor in Astronomy is a positive feat), which would act to instill confidence and motivation. Indicating an inner desire to strive for educational success, for example, is likely to result in a state of motivation (e.g., "I am motivated to work hard in order to fulfill my goal”).

As shown in Table 5, the $\Delta \chi^{2}$ tests showed an improvement in model fit, progressively, from Model $M_{0}$ to Model $M_{7}$. Aside from the $\Delta \chi^{2}$ tests, an inspection of the goodness-of-fit index values also supported the testing of different iterations of Model $\mathrm{M}_{0}$, and the acceptance of a less restrictive model. Overall, from analyses of different a posteriori models, we accept the results of Model $\mathrm{M}_{7}$ for discussion (e.g., $\chi^{2} / \mathrm{d} f=2.56$, CFI $=0.98$, TLI $=0.97$, RMSEA $=0.046)$. The solution of Model $\mathrm{M}_{7}$ is depicted in Figure 3 and, indeed, shows some interesting evidence in terms of the associations between the four latent factors: (i) that perceived social experiences positively influenced psychological processes $(\beta=0.81, p<0.001)$, motivation $(\beta=0.61, p<0.001)$, and adaptive outcomes 
TABLE 5 | Summary of fit-index values for models tested.

\begin{tabular}{|c|c|c|c|c|c|c|c|c|c|c|}
\hline \multirow[t]{2}{*}{ Model } & \multirow[t]{2}{*}{ Description of model } & \multirow[t]{2}{*}{$\chi_{2}$} & \multirow[t]{2}{*}{$\mathrm{d} f$} & \multicolumn{2}{|l|}{$\Delta \chi_{2}$} & \multirow[t]{2}{*}{ CFI } & \multirow[t]{2}{*}{ TLI } & \multicolumn{3}{|c|}{ RMSEA } \\
\hline & & & & & & & & & Lo90 & Hi90 \\
\hline $\mathrm{M}_{0}$ & $\begin{array}{l}\text { Baseline model with the following paths: Perceived social } \\
\text { experiences } \rightarrow \text { Psychological processes } \\
\text { Psychological processes } \rightarrow \text { Motivation } \\
\text { Perceived social experiences } \rightarrow \text { Motivation } \\
\text { Motivation } \rightarrow \text { Adaptive outcomes } \\
\text { Psychological processes } \rightarrow \text { Adaptive outcomes } \\
\text { Perceived social experiences } \rightarrow \text { Adaptive outcomes }\end{array}$ & 277.08 & 48 & - & & 0.94 & 0.92 & 0.080 & 0.071 & 0.090 \\
\hline $\mathrm{M}_{1}$ & $\begin{array}{l}\text { Model } \mathrm{M}_{0} \text { with the inclusion of: Pathways and means } \rightarrow \\
\text { Effective functioning }\end{array}$ & 236.04 & 47 & $\Delta_{(M 0-M 1)}=41.04$ & 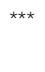 & 0.95 & 0.93 & 0.074 & 0.065 & 0.083 \\
\hline $\mathrm{M}_{2}$ & $\begin{array}{l}\text { Model } M_{1} \text { with the inclusion of: } \\
\text { Relating to others } \rightarrow \text { Self-efficacy }\end{array}$ & 202.68 & 46 & $\Delta_{(M 1-M 2)}=33.36$ & 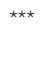 & 0.96 & 0.94 & 0.068 & 0.058 & 0.078 \\
\hline $\mathrm{M}_{3}$ & $\begin{array}{l}\text { Model } \mathrm{M}_{2} \text { with the inclusion of: } \\
\text { Personal resolve } \rightarrow \text { Adaptive outcomes }\end{array}$ & 177.94 & 45 & $\Delta_{(M 2-M 3)}=24.74$ & 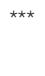 & 0.96 & 0.95 & 0.063 & 0.054 & 0.073 \\
\hline $\mathrm{M}_{4}$ & $\begin{array}{l}\text { Model } \mathrm{M}_{3} \text { with the inclusion of: } \\
\text { Pathways and means } \rightarrow \text { Personal resolve }\end{array}$ & 145.73 & 44 & $\Delta_{(M 3-M 4)}=32.21$ & 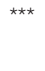 & 0.97 & 0.96 & 0.056 & 0.046 & 0.066 \\
\hline $\mathrm{M}_{5}$ & $\begin{array}{l}\text { Model } \mathrm{M}_{4} \text { with the inclusion of: Personal resolve } \rightarrow \text { Current } \\
\text { best practice }\end{array}$ & 121.39 & 43 & $\Delta_{(M 4-M 5)}=24.34$ & $\star \star \star \star ~$ & 0.98 & 0.97 & 0.050 & 0.039 & 0.060 \\
\hline$M_{6}$ & $\begin{array}{l}\text { Model } M_{5} \text { with the inclusion of: } \\
\text { Self-efficacy } \rightarrow \text { Academic liking experience }\end{array}$ & 109.42 & 42 & $\Delta_{(M 5-M 6)}=11.97$ & 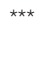 & 0.98 & 0.97 & 0.047 & 0.036 & 0.057 \\
\hline $\mathrm{M}_{7}$ & $\begin{array}{l}\text { Model } M_{6} \text { with the inclusion of: Academic striving } \rightarrow \\
\text { Motivation toward learning }\end{array}$ & 105.07 & 41 & $\Delta_{(M 6-M 7)}=4.35$ & * & 0.98 & 0.97 & 0.046 & 0.035 & 0.057 \\
\hline
\end{tabular}

${ }^{*} p<0.05,{ }^{* * *} p<0.001$

( $\beta=0.36, p<0.01$ ), (ii) the positive effect of psychological processes on motivation $(\beta=0.31, p<0.01)$, and (iii) that both psychological processes and motivation did not influence adaptive outcomes. Furthermore, of the four latent factors, evidence established indicated the potentiality for psychological processes to as a central mediator between perceived social experiences and motivation: the total effect from perceived social experiences on motivation is $0.87, p<0.001$ in which the decomposition is follows: direct effect of perceived social experiences on motivation is $0.61, p<0.001$, whereas the direct effect, mediated via psychological processes is 0.26 , $p<0.01$.

\section{DISCUSSION OF RESULTS}

A focus on effective learning and, more importantly, the proactivity of human agency within the context of academic learning is a positive endeavor for accomplishment. How do we promote mastery and/or exceptional academic performance in educational contexts? Is there an overarching system that could explain and/or account for students' effective learning and/or enriched schooling experiences? Numerous conceptualizations and research undertakings have provided comprehensive theoretical overviews, detailing comparative insights into the intricacy of the teaching and learning processes. One interesting line of inquiry, spanning the course of more than two decades relates to the positive psychology of a person, organization, and community - a state of flourishing (Keyes and Haidt, 2003; Seligman, 2010; Huppert and So, 2013), for example, is positive and reflects the enactment of the psychological processes of motivation and proactivity of a person, which may situate within his/her sociocultural system of change.

Our scholarly research interest has led to the development of a conceptual framework, which we explored in the present quantitative study. One pervasive line of inquiry that we considered, in this case, is whether and/or to what extent contrasting explanatory and predictive effects of both latent factor and measured indicator levels could positively influence different types of adaptive outcomes. In summary, evidence that we have obtained from SEM analyses is insightful, making theoretical, empirical, and methodological contributions to the study of optimal learning and schooling experiences. Figure 3, interestingly, illuminates a number of statistically significant pathways, or trajectories, which account for improvement of a student's academic learning experience. Such pathways, we contend, are informative in helping educators to design and develop different types of educational and non-educational programs for implementation.

\section{Theoretical Contributions of the Present Study}

An inspection of Figure 3 indicates a number of pathways, or trajectories, that are statistically significant, accounting $R^{2}=0.60$ for the concept of adaptive outcomes, which is made up of a student's current best practice, optimal best practice, and academic experience. An important question that we often ask, as educators, is how we would encourage and foster students' educational experiences in school or university contexts. One possible approach to this is to consider pathways, opportunities, and/or means that could assist to improve, 


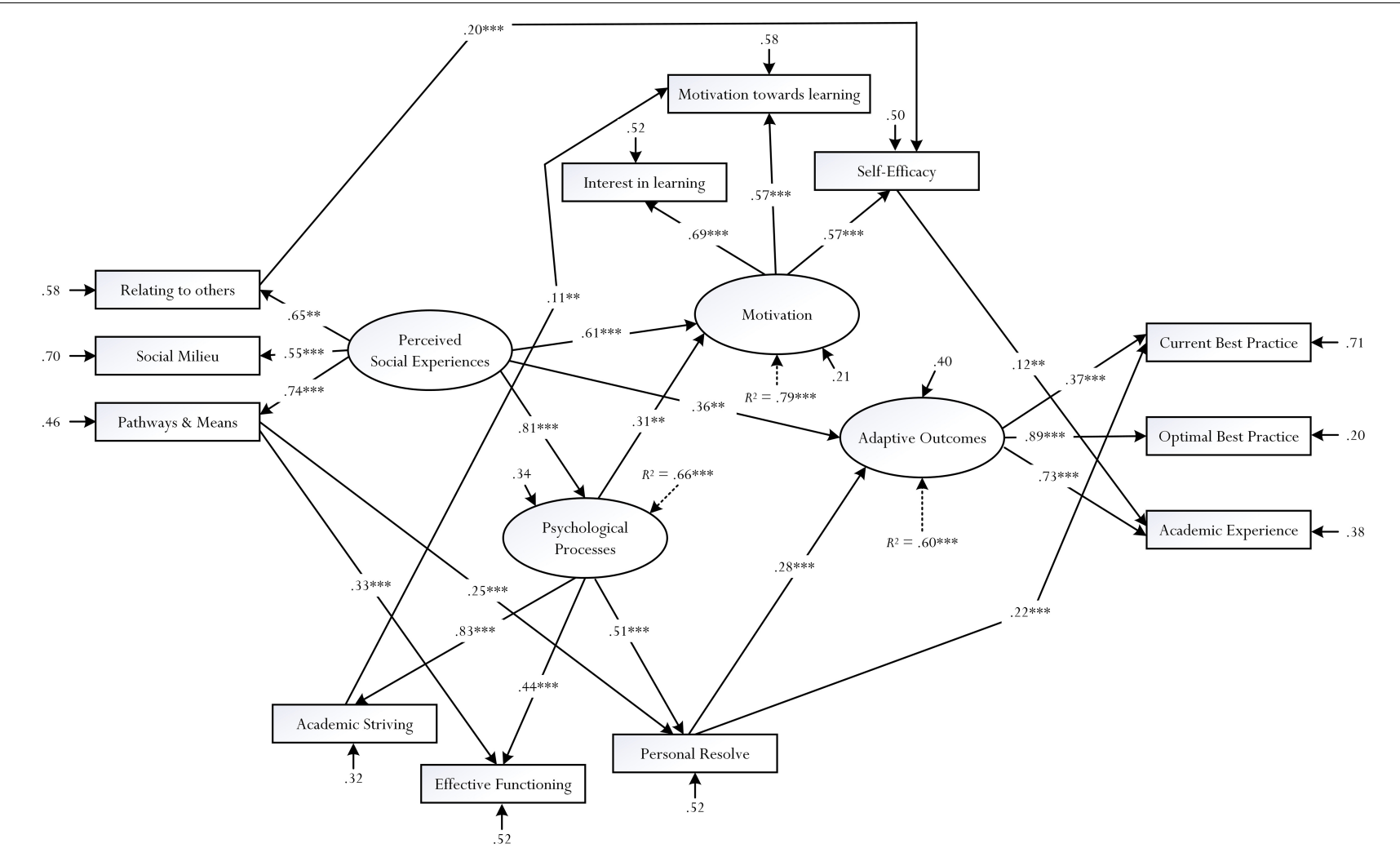

FIGURE 3 | Final solution of model M7. ${ }^{*} \boldsymbol{p}<0.05,{ }^{* *} \boldsymbol{p}<0.01,{ }^{* * *} \boldsymbol{p}<0.001$. Non-statistically significant paths have been omitted for clarity.

strengthen, and/or facilitate different students' learning and nonlearning experiences. Interestingly, as summarized below, there are a number of statistically significant pathways:

\section{(1) Predictive effects at the latent factor level:}

The effect of perceived social experiences on psychological processes.

The effect of perceived social experiences on adaptive outcomes.

The effect of perceived social experiences on motivation. The effect of psychological processes on motivation.

(2) Predictive effects at the measured indicator level:

The effect of relating to others on self-efficacy.

The effect of pathways and means on effective functioning.

The effect of pathways and means on personal resolve.

The effect of academic striving on motivation toward learning.

The effect of personal resolve on current best practice.

The effect of personal resolve on adaptive outcomes*.

The effect of self-efficacy on academic striving.

* Outcome is a latent concept - that is, a measured indicator $\rightarrow$ latent concept, where $\rightarrow=$ predictive effect.

From the above, there are five notable findings that are of significance: (i) the role of perceived social experiences as an important antecedent of psychological processes, motivation, and adaptive outcomes, (ii) the positive effect of psychological processes on motivation, (iii) the central role of psychological processes as a predictor as well as a mediator (Baron and Kenny, 1986; Trafimow, 2015), (iv) explanatory accounts and predictive effects of both latent factors (e.g., perceived social experiences $\rightarrow$ psychological processes) and measured indicators (e.g., relating to others $\rightarrow$ self-efficacy) level, and (v) empirical validation of a four-factor structure, depicting factor loadings (e.g., psychological processes consisted of personal resolve, effective functioning, and academic striving) and interrelations between the four latent factors.

What we can conclude from the established findings, as detailed in the preceding sections? There are three overarching aspects for consideration, which may advance our theoretical understanding into the positivity and proactivity of human agency. One achievement of human agency in educational contexts, in this case, relates to a student's autonomy and motivation to achieve optimal learning experiences (Phan et al., 2019b). The conclusion derived from SEM analyses contends the following:

(i) The importance of perceived social experiences: The positive effect of perceived social experiences (e.g., perception that there are pathways and means for growth) coincides with existing research development (Flook et al., 2005; Mansouri and Kamp, 2007; Roorda et al., 2011) and, in this case, 
depicts the importance of the social contexts at hand (Vygotsky, 1978; Bronfenbrenner, 1989; Lave and Wenger, 1991). For example, in a recent study, Eraslan-Capan (2016) reported that a student's perceived social connectedness (e.g., how one understands and views his/her closeness with others) positively influenced his/her state of flourishing. Interestingly, too, Flook et al. (2005) study found that negative social experiences (e.g., a student's perceived lack of peer acceptance) actually weakened both academic performance and academic self-concept. Our findings, in tandem with existing evidence, indicate that perceived social experiences, situated within different sociocultural contexts, play a notable role (e.g., helping a child to socially adjust) (Roorda et al., 2011).

(ii) Psychological sub-processes of learning: The positive effect of psychological processes on motivation supports our acknowledgment of the importance of positive psychology (Seligman and Csíkszentmihályi, 2000; Seligman et al., 2009; Seligman, 2010), as a distinct paradigm, in the teaching and learning processes. Interestingly, however, the explanatory account of psychological processes (e.g., psychological processes $\rightarrow$ motivation) reflects our proposition of its underlying nature - namely that it is consisted of three sub-processes, which have previously been examined: academic striving, effective functioning, and personal resolve. What can we draw from this finding? That in terms of accounting for motivation and/or an improvement in schooling experiences, we could consider the instilment and/or enactment of academic striving, effective functioning, and/or personal resolve. For example, evidence of the predictive role of personal resolve (e.g., personal resolve $\rightarrow$ current best practice) is consistent with existing research inquiries (e.g., Phan et al., 2018b; Phan and Ngu, 2021a), which show a positive effect of this psychological concept on different types of adaptive outcomes (e.g., task-specific self-efficacy belief for academic learning). The positive effect of academic striving on motivation toward learning, similar to previous research (Phan et al., 2020e; Phan and Ngu, 2021a), is significant, highlighting the positive nature of this psychological concept. Personal striving to accomplish a specific goal, regardless of whether one is able or not, in this sense, may act as a source of motivation, directing and motivating a person to actively engage in the learning process.

(iii) Motivation: Motivation did not statistically influence adaptive outcomes; rather, and interestingly, self-efficacy positively influenced academic liking experience and, likewise, personal resolve influenced adaptive outcomes. This evidence (i.e., self-efficacy $\rightarrow$ academic experience) supports and coincides with existing research studies (Pajares and Miller, 1994; Liem et al., 2008; Martin et al., 2010; Phan et al., 2018b), which emphasize the explanatory power of self-efficacy for academic learning (Bandura, 1977, 1997). There are two plausible reasons, however, as to why we did not find an association between the latent motivation factor and the latent adaptive outcomes factor. Firstly, there is a potential constructive "misalignment" between the two latent factors, commonly denoted as "motivation $\neq$ adaptive outcomes." Past research studies, interestingly, have alluded to a theoretical tenet known as the specificity and contextualization of motivation (Pajares, 1996b; Bandura, 1997; Phan et al., 2019d). Specificity and contextualization, in this case, emphasize the notion of microanalytical assessment and, more importantly, a close correspondence between psychological and/or achievement-related variables under examination. Secondly, our SEM analyses were somewhat "exploratory," which could in effect resulted in the testing of other iterations - for example, the removal of the direct path from the latent perceived social experiences factor to the latent adaptive outcomes factor (i.e., fixing this path to 0 ) could have resulted in a statistically significant path from the latent motivation factor to the latent adaptive outcomes factor.

\section{Practical Implications for Consideration}

The present study, aside from empirical and theoretical contributions, has also provided enriching insights for the purpose of daily relevance and practical application. This acknowledgment recognizes the importance of the nexus between research and quality teaching and learning experiences. Our focus of inquiry, differing from a deficit approach (e.g., a focus on school failure or task disengagement) (Liem et al., 2008; Henry et al., 2012), is significant for its emphasis on the proactivity and positivity of human behavior. From the perspective of schooling, in general, it is a valuable feat to focus on the promotion and encouragement of enriched student experiences, academically and/or non-academically - for example, a secondary school student may attend and enjoy school for various reasons (e.g., to partake in extracurricular activities), or a university student who enjoys her learning and seeks to engage in mastery. There are a number of educational implications that are of value for us to consider. For the purpose of conciseness, we have included Table 6, which surmises our construction of different propositions and recommendations for consideration.

An analysis of the propositions and recommendations shown in Table 6 indicates one commonly theme - namely, to consider the use of effective pedagogies, programs, institutional policies, etc., that could promote the development of psychosocial (e.g., positive social relationship at school) and/or psychological experiences (e.g., a heightened state of personal resolve), which in turn would improve engagement of different types of adaptive outcomes. Moreover, Table 6 is significant for its depiction of practical emphasis, which may differ in nature and varieties - for example, the use of verbal discourse (e.g., encouraging feedback) as opposed to exposing students to different types of metacognitive strategies. Aside from this description, what else can we consider for practicality? Recently, for example, our research inquiries have delved into the topical theme of life and death education (Chen, 2009, 2012; Huang, 2014; Phan et al., 2020c) from the perspective of Taiwanese Education. One aspect of life and death education, reflecting both quality teaching and research development, is the incorporation of Buddhist teaching (Yeshe and Rinpoche, 1976; 
TABLE 6 | A summary of educational considerations.

\section{Perceived social experiences}

- Focus on providing in-class opportunities for different types of growth (e.g., problem solving) - for example: exposing students to different challenging learning tasks and/or activities, which would encourage social interactions and, hence, discussions, debates, and collaborative learning

- Encourage and foster a positive institutional social climate for different types of growth - for example: encourage students to take part in different types of mentoring programs (e.g., the "Buddy Program" where a postgraduate student may mentor a group of 4th-year undergraduate students)
To encourage social interactions and, hence, relatedness, friendship, academic assistance, where appropriate

To encourage leadership and, more importance, social relatedness between students for different reasons - for example, social support, emotional security, and academic scaffold

To foster a positive and proactive social milieu for enriched learning experiences

\section{Psychological processes}

- Expose students to different metacognitive strategies (e.g., the use of reflective journals to record daily learning experiences)

- Provide critical, but encouraging and positive feedbacks (e.g., "You are not doing this correctly, Chou; You need to be more purposive here.... yes, excellent!")

- To purposively fail students and, hence, from this, to have students experience failures in their academic learning experiences

- Encourage students to consider and/or to record a 5-year future time plan for example, what would they realistically like to accomplish in 5 years' time?
To teach and prepare students to be more organized in their planning, organization, and reflection of learning, which emphasizes the importance of effective functioning

To teach and prepare student to be more decisive, determined, and unwavered in their decision making, which reflects the importance of personal resolve

To teach and encourage students to "bounce back" from their failures. This experience, from our point of view, reflects the importance of personal resolve

To encourage students to have aspirations for fulfillment, regardless of whether these are achievable or not. This point emphasizes the importance of academic striving for success

\section{Motivation}

- Provide encouraging feedback (e.g., "This is great, Monica! See if you can continue on with......") in a timely manner

- Situate and design subject contents to emphasize more on mastery rather than performance-based learning experiences, which would encourage competition

- Situate and design subject contents to reflect authenticity with life-related relevance, if possible
To instill confidence and, more importantly, personal self-efficacy for learning

To encourage and instill intrinsic motivation for learning

To encourage and instill interest for learning at university
Master Sheng, 2010; Thanissaro, 2015), which may encompass Buddhist mindfulness and meditation practice (e.g., "walking meditation"). The underlying premise of Buddhist teaching, in accordance with the study of life and death education, is related to the notion of "spiritual cultivation" (Phan et al., 2020c, 2021c). Buddhist meditation, in this sense, may instill and cultivate a "purified mindset," directing and assisting a person to feel more enlightened and spiritual. An interesting question then is whether and/or to what extent a spiritual mindset, via means of engagement in Buddhist meditation, say, could promote and/or predict a person's psychological processes (e.g., a person's heightened state of personal resolve).

\section{Methodological Consideration and Future Directions}

The present study has provided some important methodological insights into the measurement and assessment of psychosocial and psychological concepts. One interesting aspect of our undertaking involved the use of Likert-scale measures, situated within a non-experimental context. Non-experimental data, especially cross-sectional are extremely restricted, limiting a researcher from making casual inference and/or personal inference (Rogosa, 1979; MacCallum and Austin, 2000). By all account, the use of self-reporting is inadequate in terms of providing robust and stringent information, which could capture and/or illustrate the underlying nature and intricacy of internal psychological processes. Self-reporting is descriptive and, in this case, provides evidence of perception, judgment, feeling, and belief, all of which may indicate inaccuracy. Pajares and his colleagues researching the topic of self-efficacy for academic learning in the 1990s alluded to an interesting phenomenon, which they termed as "miscalibration" (e.g., Pajares and Miller, 1994; Pajares and Kranzler, 1995; Pajares, 1996a). Miscalibration, in this case, considers two contrasting phenomena: a state of overconfidence versus a state of underconfidence. In the context of the present study then, it is plausible to contend that a university student may miscalibrate and report, for example, a high level of personal resolve or effective functioning. In a similar vein, a secondary school student may have some form of grievance toward his teacher, resulting in a biased report that indicates very little, if any, academic and/or social support at school (i.e., a biased indication of the indicator of pathways, means, and opportunities). On this basis, we argue for the use of alternative methodological designs, which could address the aforementioned shortcomings. 
An interesting observation that we note, which has potential methodological relevance relates to in situ observations may complement the use of "meditative reflection" and subsequent self-reporting of personal feelings and experiences (Phan et al., 2021c). Meditative reflection and self-reporting, as a whole, is internal and arises from within a student (i.e., subjective in nature), whereas a teacher's in situ observation of the student is external (i.e., objective in nature). This consideration of using multiple strategies of data collection, we contend, is more effective as this could provide a balanced, well-rounded viewpoint and/or testament (i.e., subjective versus objective) of a person's behavior, psychological thoughts, emotions, experiences, etc. As such, contrasting methodological strategies may add credence to assist in the validation and elucidation of a process, relationship, etc.

We posit that the hypothesized relationships depicted in Figure $\mathbf{1}$ and/or the obtained solution shown in Figure $\mathbf{2}$ are somewhat complex and as such, as we previously mentioned, using cross-sectional and non-experimental data is inadequate. We encourage the use of longitudinal data as these could offer a more robust methodological approach in validating and/or substantiating long-term flow and personal growth. As an example, which may support our rationale, the underlying nature of academic striving (e.g., Phan and Ngu, 2020a, 2021a; Phan et al., 2020e) is complex and would, in this instance, require longitudinal data for accurate assessment and theoretical understanding. When a person aspires and strives to achieve an optimal state of functioning (Fraillon, 2004; Liem et al., 2012; Phan et al., 2016c), he/she would require time, effort, the availability of resources, etc. As such, in terms of appropriateness, we advocate for the use of multiple time points in data collection as this longitudinal consideration would offer a logical and more accurate capture of a student's personal resolve, striving, etc., for example, a student may indicate to us the following $\left(\mathrm{T}_{1}\right)$ : "I want to strive and achieve Honors in Psychology by the time I graduate" (Date of indication, for example: 13th May, 2020). The question then is whether this mentioning of aspiration and personal striving would eventuate in 2 years' time, when the student would have completed her academic studies $\left(\mathrm{T}_{2}\right)$.

Finally, one of our reviewers provided some interesting methodological insights, which we deem may play a critical role in future research development. The study of perceptions (e.g., a perception of positive social experience versus negative social experience), especially when it comes to diversity and sampling requires formal recognition and acknowledgment of potential selection bias and limitations. For example, as the reviewer highlights, our participants came from different universities and departments and consequently, from this variation and/or diversity, their individual differences were not well controlled. Thus, from this observation of "dissimilar" backgrounds, we urge readers to read and interpret our results with caution. In a similar vein, of course, our own observation recognizes that the sample was relatively modest in size, limiting us from undertaking additional and/or different types of statistical analysis - for example, a statistical undertaking, which involves a factorial variance/invariance analysis, identifying potential equivalency (Byrne, 1998) between different groupings (e.g., the extent to which the final solution depicted in Figure 3 is invariant across both men and women). A larger sample size, situated within hierarchical clusters or structures (e.g., universities $\times$ faculties $\times$ schools $\times$ departments), likewise, may provide opportunities for multilevel modeling (Little, 2000).

\section{CONCLUSION}

The present study tested a conceptual model, which considered three distinct but interrelated theoretical orientations within a system of change: psychosocial influences, positive motivational beliefs, and psychological processes. Established evidence via means of correlational analysis is of significance, detailing specific pathways that could account for an improvement in a person's adaptive outcomes. The statistical techniques of SEM, interestingly, offer logical grounding for the analysis and study of associations between both latent (e.g., the positive effect of psychological processes on motivation) and measured indicator (e.g., the positive effect of self-efficacy on academic experience) levels. Aside from empirical, theoretical, and methodological contributions, our research undertaking also provided sound, meaningful insights for educational purposes.

\section{DATA AVAILABILITY STATEMENT}

The original contributions presented in the study are included in the article/supplementary material, further inquiries can be directed to the corresponding author.

\section{ETHICS STATEMENT}

The studies involving human participants were reviewed and approved by the University of New England Research Ethics Committee. Written informed consent for participation was not required for this study in accordance with the national legislation and the institutional requirements.

\section{AUTHOR CONTRIBUTIONS}

$\mathrm{HP}$ and $\mathrm{BN}$ contributed equally to the conceptualization, articulation, and writing of the manuscript. Both authors contributed to the article and approved the submitted version.

\section{ACKNOWLEDGMENTS}

We sincerely thank the Associate Editor and the two reviewers for their insightful comments and suggestions, which have improved the quality and re-articulation of this article. 


\section{REFERENCES}

Acu and Erebus International (2008). Scoping study into approaches to student wellbeing: Literature review. Report to the Department of Education, Employment and Workplace Relations. Sydney: Australian Catholic University.

Ainsworth, M. D. S. (1979). Infant-mother attachment. Am. Psychol. 34:932.

Ainsworth, M. D. S., Blehar, M. C., Waters, E., and Wall, D. (1978). Patterns of attachment: A psychological study of the strange situation. Hillsdale, NJ: Lawrence Erlbaum.

Allen, J., Gregory, A., Mikami, A., Lun, J., Hamre, B., and Pianta, R. (2013). Observations of effective teacher-student interactions in secondary school classrooms: predicting student achievement with the classroom assessment Sscoring system-secondary. Sch. Psychol. Rev. 42, 76-98.

Bandura, A. (1977). Self-efficacy: Toward a unifying theory of behavioral change. Psychol. Rev. 84, 191-215. doi: 10.1037//0033-295x.84.2.191

Bandura, A. (1997). Self-efficacy: The exercise of control. New York: W. H. Freeman \& Co.

Baron, R. M., and Kenny, D. A. (1986). The moderator-mediator variable distinction in social psychological research: conceptual, strategic, and statistical considerations. J. Pers. Soc. Psychol 51, 1173-1182.

Bollen, K. A. (1989). Structural equations with latent variables. New York: Wiley.

Bronfenbrenner, U. (1989). "Ecological systems theory," in Annals of child development: Theories of child development: Revised formulations and current issues, ed. R. Vasta (Greenwich, CT: JAI Press), 187-251.

Byrne, B. M. (1998). Structural equation modelling with LISREL, PRELIS, and SIMPLIS. Mahwah, NJ: Erlbaum.

Byrne, B. M. (2012). Structural equation modeling with Mplus: Basic concepts, applications, and programming. New York, NY: Taylor \& Francis Group.

Chen, S. C. (2009). The fusion of life and health-spiritual education. Nat. Educ. 50, 7-13.

Chen, S. C. (2012). Oriental humanities, mindfulness and life education." Life Education Symposium. Taipei City: International Conference on Life Education.

Chen, S. C. (2017). Constructing campus culture with Life Education: Taking the education of HuaFan University as an example. Taipei City: International Conference on Life Education.

Collie, R. J., Martin, A. J., Malmberg, L. E., Hall, J., and Ginns, P. (2015). Academic buoyancy, student's achievement, and the linking role of control: a cross-lagged analysis of high school students. Br. J. Educ. Psychol. 85, 113-130. doi: 10.1111/ bjep. 12066

Csíkszentmihályi, M. (1990). Flow: The psychology of optimal experience. New York, NY: Harper Perennial.

De Fraine, B., Landeghem, G. V., Van Damme, J., and Onghena, P. (2005). An analysis of well-being in secondary school with multilevel growth curve models and multilevel multivariate models. Qual. Quan. 39, 297-316.

Deci, E. L., and Ryan, R. M. (1991). “A motivational approach to self: Integration in personality," in Nebraska symposium on motivation: Vol. 38, Perspectives on motivation, ed. R. Dienstbier (Lincoln, NE: University of Nebraska Press), 237-288.

Deci, E. L., and Ryan, R. M. (2008). Self-determination theory: a macrotheory of human motivation, development, and health. Can. Psychol. 49, 182-185. doi: 10.1037/ocp0000177

Diener, E., Wirtz, D., Tov, W., Kim Prieto, C., Choi, D. W., Oishi, S., et al. (2010). New well-being measures: Short scales to assess flourishing and positive and negative feelings. Soc. Indicat. Res. 97, 143-156. doi: 10.1007/s11205-0099493-y

Diseth, A. (2011). Self-efficacy, goal orientations and learning strategies as mediators between preceding and subsequent academic achievement. Learn. Ind. Diff. 21, 191-195.

Eccles, J. S., Adler, T. F., Futterman, R., Goff, S. B., Kaczala, C. M., Meece, J. L., et al. (1983). "Expectancies, values and academic behaviors," in Achievement and achievement motives, ed. J. T. Spence (San Francisco: W. H. Freeman), 75-146.

Eraslan Capan, B. (2016). Social connectedness and flourishing: The mediating role of hopelessness. Univer. J. Edu. Res. 4, 933-940.

Flook, L., Repetti, R. L., and Ullman, J. B. (2005). Classroom social experiences as predictors of academic performance. Develop. Psychol. 41, 319-327.

Forbes, S. H. (2003). Holistic education: An analysis of its ideas and nature. Brandon, VT: Foundation for Edcational Renewal.
Fraillon, J. (2004). Measuring student well-being in the context of Australian schooling: Discussion Paper. Carlton South, Victoria: The Australian Council for Research.

Franken, R. E. (2007). Human motivation. $6^{\text {th }}$ ed. Belmont, CA: Thomson Wadsworth.

Gallagher, E. (2013). The effects of teacher-student relationships: social and academic outcomes of low-income middle and high school students. Appl. Psychol. OPUS 5, 12-15.

Green, J., Liem, G. A., Martin, A. J., Colmar, S., Marsh, H. W., and McInerney, D. (2012). Academic motivation, self-concept, engagement, and performance in high school: key processes from a longitudinal perspective. J. Adol. 35, 1111-1122. doi: 10.1016/j.adolescence.2012.02.016

Hare, J. (2010). Holistic education: An interpretation for teachers in the IB programmes, International Baccalaureate. Geneva: International Baccalaureate Organization.

Hawkins, A., Barbour, M. K., and Graham, C. R. (2010). Teacher-student interaction and academic performance at Utah's Electronic High School." $26^{\text {th }}$ Annual Conference on Distance Teaching \& Learning. Madison.

Henry, K. L., Knight, K. E., and Thornberry, T. P. (2012). School disengagement as a predictor of dropout, delinquency, and problem substance use during adolescence and early adulthood. J. Youth Adol. 41, 156-166. doi: 10.1007/ s10964-011-9665-3

Huang, J. (2014). New orientation of life education in the 21st century: Spiritual awakening, classic study and environmental education.Taipei City: The Sheng Yen Education Foundation. doi: 10.1007/s10964-0119665-3

Huppert, F. A., and So, T. T. (2013). Flourishing across Europe: application of a new conceptual framework for defining well-being. Soc. Indic. Res. 110, 837-861. doi: 10.1007/s11205-011-9966-7

Jöreskog, K. G., and Sörbom, D. (2001). LISREL 8: User's reference guide [software manual]. Chicago: Scientific Software.

Keyes, C. L. M., and Haidt, J. (2003). Flourishing: Positive psychology and the life well lived. 1st ed. Washington DC: American Psychological Association.

Kline, R. B. (2011). Principles and practice of structural equation modeling. 3rd ed. New York, NY: The Guilford Press.

Lave, J., and Wenger, E. (1991). Situated learning: Legitimate peripheral participation. Cambridge, MA: Cambridge University Press.

Lent, R. W., Lopez, F. G., and Bieschke, K. J. (1991). Mathematics self-efficacy: Sources and relation to science-based career choice. J. Coun. Psychol. 38, 424-430. doi: 10.1037//0022-0167.38.4.424

Li, J., McMurray, A., and Stanley, F. (2008). Modernity's paradox and the structural determinants of child health and wellbeing. Health Soc. Rev. 17, 64-77.

Liem, A. D., Lau, S., and Nie, Y. (2008). The role of self-efficacy, task value, and achievement goals in predicting learning strategies, task disengagement, peer relationship, and achievement outcome. Contem. Edu. Psychol. 33, 486-512. doi: 10.1016/j.cedpsych.2007.08.001

Liem, G. A. D., and Martin, A. J. (2011). Peer relationships and adolescents' academic and non-academic outcomes: Same-sex and opposite-sex peer effects and the mediating role of school engagement. Br. J. Edu. Psychol. 81, 183-206. doi: 10.1111/j.2044-8279.2010.02013.x

Liem, G. A. D., Ginns, P., Martin, A. J., Stone, B., and Herrett, M. (2012). Personal best goals and academic and social functioning: a longitudinal perspective. Lear. Ins. 22, 222-230. doi: 10.1016/j.learninstruc.2011.11.003

Little, T. D. (2000). Modeling longitudinal and multilevel data: Practical issues, applied approaches, and specific examples. Mahwah, NJ: Lawrence Erlbaum.

MacCallum, R. C., and Austin, J. T. (2000). Applications of structural equation modeling in psychological research. Annu. Rev. Psychol. 51, 201-226. doi: 10. 1146/annurev.psych.51.1.201

Mansouri, F., and Kamp, A. (2007). Structural deficiency or cultural racism: The educational and social experiences of Arab-Australian youth. Aus. J. Soc. Iss. 42, 87-102.

Martin, A. J. (2006). Personal bests (PBs): a proposed multidimensional model and empirical analysis. Br. J. Edu. Psychol. 76, 803-825. doi: 10.1348/ 000709905X55389

Martin, A. J., Colmar, S. H., Davey, L. A., and Marsh, H. W. (2010). Longitudinal modelling of academic buoyancy and motivation: do the 5Cs hold up over time? Br. J. Edu. Psychol. 80, 473-496. doi: 10.1348/000709910X486376 
Martin, A. J., Ginns, P., Brackett, M. A., Malmberg, L. E., and Hall, J. (2013). Academic buoyancy and psychological risk: Exploring reciprocal relationships. Learn. Ind. Diff. 27, 128-133. doi: 10.1016/j.lindif.2013.06.006

Maslow, A. H. (1968). Toward a psychology of being. Princeton, NJ: Van Nostrand Reinhold.

Maslow, A. H. (1970). Motivation and personality, 2nd Edn. New York, NY: Viking Press.

Master Sheng, Y. (2010). The Dharma Drum Lineage of Chan Buddhism: Inheriting the past and inspiring the future. Taipei City: The Sheng Yen Education Foundation.

Muthén, L. K., and Muthén, B. O. (1998-2012). Mplus User's Guide. 7th Edn. Los Angeles, CA: Muthén \& Muthén.

Ngu, B. H., Phan, H. P., Wang, H.-W., Shih, J.-H., Shi, S.-Y., and Lin, R.-Y. (2019). "Best practice in mathematics learning: A theoretical discussion for consideration," in Progress in education, ed. R. V. Nata (New York, NY: Nova Science Publishers), 79-112. doi: 10.1016/j.envres.2019.05.049

Nsw Department of Education and Communities. 2015. The Wellbeing Framework for schools. ed NSW Department of Education and Communities. Sydney: NSW Department of Education and Communities. doi: 10.1016/j.envres.2019. 05.049

Pajares, F. (1996a). Self-Efficacy beliefs and mathematical problem-solving of gifted students. Contemp. Edu. Psychol. 21, 325-344. doi: 10.1006/ceps.1996.0025

Pajares, F. (1996b). Self-efficacy beliefs in academic settings. Rev. Edu. Res. 66, 543-578. doi: 10.2307/1170653

Pajares, F., and Kranzler, J. (1995). Self-efficacy beliefs and general mental-ability in mathematical problem-solving. Contem. Edu. Psychol. 20, 426-443. doi: 10. 1006/ceps.1995.1029

Pajares, F., and Miller, M. D. (1994). Role of self-efficacy and self-concept beliefs in mathematical problem-solving: A path analysis. J. Edu. Psychol. 86, 193-203. doi: 10.1037//0022-0663.86.2.193

Pajares, F., Britner, S. L., and Valiante, G. (2000). Relation between achievement goals and self-beliefs of middle school students in writing and science. Contem. Edu. Psychol 25, 406-422. doi: 10.1006/ceps.1999.1027

Pajares, F., Johnson, J., and Usher, E. L. (2007). Sources of writing self-efficacy beliefs of elementary, middle, and high school students. Res. Teach. Eng. 42, 104-120.

Phan, H. P. (2012). Informational sources, self-efficacy, and achievement: A temporally displaced approach. Edu. Psychol. 32, 699-726. doi: 10.1080/ 01443410.2012 .708320

Phan, H. P. (2017a). The self-systems: Facilitating personal well-being experiences at school. Soc. Psychol. Edu. 20, 115-138. doi: 10.1007/s11218-016-9350-1

Phan, H. P., and Ngu, B. H. (2014). The Academic Optimized Functioning Questionnaire (AOFQ). Armidale, NSW: UNE.

Phan, H. P., and Ngu, B. H. (2016a). "Optimal outcomes: A focus on theoretical tenets for consideration," in Deep learning: Fundamentals, methods and applications, ed. J. Porter (New York, NY: Nova Publishing), 33-60.

Phan, H. P., and Ngu, B. H. (2018a). An examination of social and psychological influences on academic learning: a focus on self-esteem, social relationships, and personal interest. Soc. Psychol. Edu. 21, 51-73. doi: 10.1007/s11218-0179407-9

Phan, H. P., and Ngu, B. H. (2019a). Teaching, Learning and Psychology. Docklands. Melbourne: Oxford University Press.

Phan, H. P., and Ngu, B. H. (2020a). Schooling experience and academic performance of Taiwanese students: The importance of psychosocial effects, positive emotions, levels of best practice, and personal well-being. Soc. Psychol. Edu. 23, 1073-1101. doi: 10.1007/s11218-020-09569-9

Phan, H. P., and Ngu, B. H. (2021a). Optimization: An attempt to establish empirical evidence for theoretical and practical purposes. Eur. J. Psychol. Edu. 36, 453-475. doi: 10.1007/s10212-020-00484-3

Phan, H. P., and Ngu, B. H. (2021b). Perceived 'optimal efficiency': theorization and conceptualization for development and implementation. Heliyon 7:e06042. doi: 10.1016/j.heliyon.2021.e06042

Phan, H. P., Ngu, B. H., and Alrashidi, O. (2016b). Roles of student well-being: a study using structural equation modeling. Psychol. Rep. 119, 77-105. doi: 10.1177/0033294116656819

Phan, H. P., Ngu, B. H., and Alrashidi, O. (2018b). Contextualised self-beliefs in totality: an integrated framework from a longitudinal perspective. Edu. Psychol. 38, 411-434. doi: 10.1080/01443410.2017.1356446
Phan, H. P., Ngu, B. H., and McQueen, K. (2020b). Future time perspective and the achievement of optimal best. Front. Psychol. 11, 1-13. doi: 10.3389/fpsyg.2020. 01037

Phan, H. P., Ngu, B. H., and Williams, A. (2015). The Optimal Outcomes Questionnaire. Armidale, NSW: Education UNE.

Phan, H. P., Ngu, B. H., and Williams, A. (2016c). Introducing the concept of Optimal Best: Theoretical and methodological contributions. Education 136, 312-322.

Phan, H. P., Ngu, B. H., and Yeung, A. S. (2017b). Achieving optimal best: Instructional efficiency and the use of cognitive load theory in mathematical problem solving. Edu. Psychol. Rev. 29, 667-692. doi: 10.1007/s10648-0169373-3

Phan, H. P., Ngu, B. H., and Yeung, A. S. (2019b). Optimization: In-depth examination and proposition. Front. Psychol. 10, 1-16. doi: 10.3389/fpsyg.2019. 01398

Phan, H. P., Ngu, B. H., Chen, S. C., Wu, L., Shi, S.-Y., Shih, J.-H., et al. (2020d). Advancing the study of positive psychology: the use of a multifaceted structure of mindfulness for development. Front. Psychol 11:1-19. doi: 10.3389/fpsyg. 2020.01602

Phan, H. P., Ngu, B. H., Chen, S.-C., Wu, L., Lin, W.-W., and Hsu, C.-S. (2020c). Introducing the study of life and death education to support the importance of positive psychology: $n$ integrated model of philosophical beliefs, religious faith, and spirituality. Front. Psychol. 11:1-16. doi: 10.3389/fpsyg.2020.580186

Phan, H. P., Ngu, B. H., Chen, S.-C., Wu, L., Shih, J.-H., and Shi, S.-Y. (2021c). Life, death, and spirituality: A conceptual analysis for educational research development. Heliyon 7:e06971. doi: 10.1016/j.heliyon.2021.e06971

Phan, H. P., Ngu, B. H., Lin, R.-Y., Wang, H.-W., Shih, J.-H., and Shi, S.-Y. (2019c). Predicting and enhancing students' positive emotions: An empirical study from a Taiwanese sociocultural context. Heliyon 5:e02550. doi: 10.1016/j.heliyon. 2019.e02550

Phan, H. P., Ngu, B. H., Shih, J.-H., Lin, R.-Y., Shi, S.-Y., and Wang, H.-W. (2020e). Validating newly developed 'optimizing' concepts: the importance of personal resolve, effective functioning, and academic striving. Edu. Psychol. 40, 448-472. doi: 10.1080/01443410.2019.1693507

Phan, H. P., Ngu, B. H., Wang, H.-W., Shih, J.-H., Shi, S.-Y., and Lin, R.-Y. (2018). Understanding levels of best practice: an empirical development. PloS One 13:198888. doi: 10.1371/journal.pone.0198888

Phan, H. P., Ngu, B. H., Wang, H.-W., Shih, J.-H., Shi, S.-Y., and Lin, R.-Y. (2019d). Achieving optimal best practice: An inquiry into its nature and characteristics. PLoS One 14:e0215732. doi: 10.1371/journal.pone.0215732

Pintrich, P. R., and Schunk, D. H. (2002). Motivation in education: Theory, research and applications. Upper Saddle River, NJ: Prentice-Hall Merrill.

Pintrich, P. R., Smith, D. A. F., Garcia, T., and McKeachie, W. J. (1993). Reliability and predictive validity of the motivated strategies for learning questionnaire (MSLQ). Edu. Psychol. Meas. 53, 810-814.

Pintrich, P. R., Smith, D. A. F., Garcia, T., and McKeachie, W. J. (1991). A manual for the use of the Motivated Strategies for Learning Questionnaire (MSLQ). Ann Arbor, MI: National Centre for Research to Improve Postsecondary Teaching and Learning.

Raufelder, D., Danilo, J., Kate, D., and Frances, H. (2013). Social relationships and motivation in secondary school: Four different motivation types. Learn. Ind. Diff. 24, 89-95.

Rogosa, D. (1979). "Causal models in longitudinal research: Rationale, formulation, and interpretation," in Longitudinal research in the study of behaviour and development, eds J. R. Nesselroade and P. B. Balles (New York: Academic Press), 263-302.

Roorda, D. L., Koomen, H. M. Y., Spilt, J. L., and Oort, F. J. (2011). The influence of affective teacher-student relationships on students' school engagement and achievement: a meta-analytic approach. Rev. Edu. Res. 81, 493-529. doi: 10. 3102/0034654311421793

Roseth, C. J., Johnson, D. W., and Johnson, R. T. (2008). Promoting early adolescents' achievement and peer relationships: the effects of cooperative, competitive, and individualistic goal structures. Psychol. Bull. 134, 223-246. doi: 10.1037/0033-2909.134.2.223.supp

Sansone, C., and Harackiewicz, M. J. (2000). Intrinsic and extrinsic motivation: The search for optimal motivation and performance. Cambridge: Academic Press.

Schumacker, R. E., and Lomax, R. G. (2004). A beginner's guide to structural equation modeling, 2nd Edn. Mahwah, NJ: Lawrence Erlbaum Associates, Inc. 
Schunk, D. H. (1995). "Self-efficacy and education and instruction," in Self-efficacy, adaptation, and adjustment: Theory, research and application, ed. J. E. Maddux (New York: Plenum Press), 283-301.

Schunk, D. H., and Meece, J. L. (2006). Self-efficacy development in adolescence. Self-Eff. Beliefs Adoles. 5, 71-96.

Schunk, D. H., Pintrich, P. R., and Meece, J. L. (2008). Motivation in education: Theory, research, and applications, 3rd Edn. Upper Saddle River, NJ: Pearson, Merrill, Prentice Hall.

Seligman, M. (1999). The president's address. Am. Psychol. 53, 559-562.

Seligman, M. (2010). Flourish: Positive psychology and positive interventions." The Tanner Lectures on Human Values.Ann Arbor: University of Michigan.

Seligman, M., and Csíkszentmihályi, M. (2000). Positive psychology: An introduction. American Psychologist 55, 5-14. doi: 10.1037//0003-066x.55.1.5

Seligman, M., Ernst, R. M., Gillham, J., Reivich, K., and Linkins, M. (2009). Positive education: Positive psychology and classroom interventions. Oxford Rev. Edu. 35, 293-311. doi: 10.1080/03054980902934563

Senko, C., and Miles, K. M. (2008). Pursuing their own learning agenda: How mastery-oriented students jeopardize their class performance. Contemp. Edu. Psychol. 33, 561-583. doi: 10.1016/J.Cedpsych.2007.12.001

Shehu, A., Zhilla, E., and Dervishi, E. (2015). The impact of the quality of social relationships on self-esteem of children with dyslexia. Eur. Sci. J. 11, 308-318. doi: $10.1111 /$ camh. 12331

Soutter, A. K. (2011). What can we learn about wellbeing in school? J. Stud. Well. $5,1-21$.

Stevenson-Hinde, J., and Verschueren, K. (2002). "Attachment in childhood", in Blackwell handbook of childhood social development, eds P. Smith and C. Hart (Oxford: Blackwell), 182-204.

Su, R., Tay, L., and Diener, E. (2014). The development and validation of the Comprehensive inventory of thriving (CIT) and the brief inventory of thriving (BIT). Appl. Psychol. 6, 251-279. doi: 10.1111/aphw.12027

Tam, W. M. (2011). Hidden school disengagement and its relationship to youth risk behaviors in Hong Kong. Edu. Res. J. 26, 175-197.

Thagard, P. (2014). The self as a system of multilevel interacting mechanisms. Philosophic. Psychol. 27, 145-163. doi: 10.1080/09515089.2012.725715

Thagard, P. (2018). Mind, consciousness, and free will. Front. Philosophy China 13:377-393. doi: 10.3868/s030-007-018-0029-2

Thanissaro, P. N. (2015). The spirituality of Buddhist teens: religious/spiritual experiences and their associated triggers, attributes and attitudes. Int. J. Child. Spiritual. 20, 218-232. doi: 10.1080/1364436X.2015.1118680

Trafimow, D. (2015). Introduction to the special issue on mediation analyses: What if planetary scientists used mediation analysis to infer causation? Basic Appl. Soc. Psychol. 37, 197-201. doi: 10.1080/01973533.2015.106 4290

Umberson, D., and Montez, J. K. (2010). Social relationships and health: A flashpoint for health policy. J. Health Soc. Behav. 51, 54-66. doi: 10.1177/ 0022146510383501

Upadyaya, K., Viljaranta, J., Lerkkanen, M. K., Poikkeus, A. M., and Nurmi, J. E. (2011). Cross-lagged relations between kindergarten teachers' causal attributions, and children's interest value and performance in mathematics. Soc. Psychol. Edu. 15, 181-206. doi: 10.1007/s11218-011-9171-1

Usher, E. L., and Pajares, F. (2006). Sources of academic and self-regulatory efficacy beliefs of entering middle school students. Contemp. Edu. Psychol. 31, 125-141.

Usher, E. L., and Pajares, F. (2008). Sources of self-efficacy in school: Critical review of the literature and future directions. Rev. Edu. Res. 78, 751-796.

Van Damme, J., De Fraine, B., Van Landeghem, G., Opdenakker, M.-C., and Onghena, P. (2002). A new study on educational effectiveness in secondary schools in Flanders: An introduction. School Effectiveness and School Improvement. Int. J. Res. Policy Prac. 13, 383-397.

Van De Gaer, E., De Fraine, B., Pustjens, H., Van Damme, J., De Munter, A., and Onghena, P. (2009a). School effects on the development of motivation toward learning tasks and the development of academic self-concept in secondary education: a multivariate latent growth curve approach. Sch. Effect. Sch. Improve. 20, 235-253. doi: 10.1080/09243450902883920

Van De Gaer, E., Pustjens, H., Van Damme, J., and De Munter, A. (2009b). School engagement and language achievement: a longitudinal study of gender differences across secondary school. J. Dev. Psychol. 55, 373-405.

Vygotsky, L. (1978). Mind in society: The development of higher psychological processes. Cambridge, MA: Harvard University Press.

Vygotsky, L. (1981). “The genesis of higher mental functions," in The concept of activity in Soviet Psychology, ed. J. V. Wertsch (Armonk, NY: Sharpe), 144-188.

Walkington, C. A. (2013). Using adaptive learning technologies to personalize instruction to student interests: The impact of relevant contexts on performance and learning outcomes. J. Edu. Psychol. 105, 932-945.

Waters, L., Sun, J., Rusk, R., Cotton, A., and Arch, A. (2017). "Positive Education: Visible wellbeing and the five domains of positive functioning," in Wellbeing, recovery mental health, eds $\mathrm{M}$. Slade, L. Oades, and A. Jarden (UK: Cambridge University Press), 245-264.

Weiner, B. (1972). Attribution theory, achievement motivation, and the educational process. Rev. Edu. Res. 42, 203-215.

Weiner, B. (1986). An attributional theory of motivation and emotion. New York, NY: Springer.

Wentzel, K. R. (1998). Social relationships and motivation in middle school: The role of parents, teachers, and peers. J. Edu. Psychol. 90, 202-209. doi: 10.1186/ s12913-016-1423-5

Whannell, R., and Allen, W. (2011). High school dropouts returning to study : the influence of the teacher and family during secondary school. Aus. J. Teach. Edu. 36, 22-35. doi: 10.14221/ajte.2011v36n9.3

Wiese, C. W., Tay, L., Su, R., and Diener, E. (2018). Measuring thriving across nations: Examining the measurement equivalence of the Comprehensive Inventory of Thriving (CIT) and the Brief Inventory of Thriving (BIT). App. Psychol. 10, 127-148. doi: 10.1111/aphw.12119

Wigfield, A., and Eccles, J. S. (2000). Expectancy-value theory of achievement motivation. Contemp. Edu. Psychol. 25, 68-81. doi: 10.1006/ceps.1999.1015

Yeshe, L., and Rinpoche, L. Z. (1976). Wisdom energy: Basic Buddhist teachings. Somerville, MA: Wisdom Publications.

Conflict of Interest: The authors declare that the research was conducted in the absence of any commercial or financial relationships that could be construed as a potential conflict of interest.

Publisher's Note: All claims expressed in this article are solely those of the authors and do not necessarily represent those of their affiliated organizations, or those of the publisher, the editors and the reviewers. Any product that may be evaluated in this article, or claim that may be made by its manufacturer, is not guaranteed or endorsed by the publisher.

Copyright (C) 2021 Phan and Ngu. This is an open-access article distributed under the terms of the Creative Commons Attribution License (CC BY). The use, distribution or reproduction in other forums is permitted, provided the original author(s) and the copyright owner(s) are credited and that the original publication in this journal is cited, in accordance with accepted academic practice. No use, distribution or reproduction is permitted which does not comply with these terms. 